\title{
Foundations and Emerging Paradigms for Computing in Living Cells
}

\author{
Kevin C. Ma ${ }^{1}$, Samuel D. Perli ${ }^{1}$, and Timothy K. Lu ${ }^{1, *}$
}

${ }^{1}$ Synthetic Biology Group, Research Laboratory of Electronics, Department of Biological Engineering and Electrical Engineering \& Computer Science, Massachusetts Institute of Technology, Cambridge, MA 02142, USA

${ }^{*}$ Correspondence: timlu@mit.edu 


\begin{abstract}
Genetic circuits, composed of complex networks of interacting molecular machines, enable living systems to sense their dynamic environments, perform computation on the inputs and formulate appropriate outputs. By rewiring and expanding these circuits with novel parts and modules, synthetic biologists have adapted living systems into vibrant substrates for engineering. Diverse paradigms have emerged for designing, modeling, constructing, and characterizing such artificial genetic systems. In this paper, we first provide an overview of recent advances in the development of genetic parts and highlight key engineering approaches. We then review the assembly of these parts into synthetic circuits from the perspectives of digital \& analog logic, systems biology, and metabolic engineering, three areas of particular theoretical and practical interest. Finally, we discuss notable challenges that the field of synthetic biology still faces in achieving reliable and predictable forward-engineering of artificial biological circuits.
\end{abstract}




\section{Introduction}

Since the design of the bacterial toggle switch and the bacterial oscillator in 2000 [1, 2], researchers in the multi-disciplinary field of synthetic biology have developed innovations in the areas of cellular computing [3, 4], bio-sensing [5-14], biochemicals [15-20], therapeutics and diagnostics [21-25], pharmaceuticals manufacturing [26-28], and biomaterials [29-35]. With the advent of high-throughput methods to construct and characterize genetic circuits and the continually decreasing costs of DNA synthesis \& sequencing [36], synthetic biology is well-poised to continue contributing to areas ranging from answering unsolved questions of biology to generating novel solutions for today's pressing challenges in healthcare and the environment [37].

In this review, we begin with a look at the fundamental engineering principles that have guided the early phases of research in synthetic biology and highlight recent major advances in part development at the DNA, RNA, \& protein level. We then turn to strategies that have guided the assembly of these parts into higher-order constructs. Ideas and implementations of novel synthetic circuits have routinely come from the importation of ideas and design principles from other fields; we apply particular focus on the intersection of synthetic biology with digital \& analog computing, systems biology, and metabolic engineering. These perspectives and specific applications often determine how a bioengineer will approach the design process for a synthetic circuit, from core conceptual models to methods of characterization to desired outputs. Ultimately, as the ability of synthetic biologists to predictably engineer complex circuits continues to increase, we expect to see even greater diversity in the inspiration for and application of synthetic gene circuits. 


\section{Engineering Components}

\section{Gene regulatory parts}

Biological systems operate in dynamic environmental contexts where they sense and respond to various forms of stimuli. The inputs sensed by engineered synthetic circuits are application specific and include signals represented by different combinations of small-molecule chemicals, light, heat, mechanical stimuli, and others. Synthetic circuits translate inputs into specific outputs based on the desired function. The outputs of synthetic circuits have conventionally been RNA or proteins. Fluorescent proteins are typically used while testing synthetic circuits, whereas proteins with physiological, therapeutic or commercial relevance are selected based on the application of interest [38, 39]. In recent years, the number of parts developed to enable the construction of a wide range of synthetic gene circuits has become large. We briefly review advances in the development of biological parts; for another overview see Table 1 in Wang et al. [40].

Early synthetic circuits in prokaryotic systems focused on regulation of transcription through well-characterized, inducible transcription factors [1, 2]. The activity of many of these transcription factors can be controlled via small-molecule inducers, such as the transcription factors Lacl, AraC, and TetR, which respond to chemical induction by isopropyl $\beta$-D-1-thiogalactopyranoside (IPTG), arabinose, and anhydrotetracycline, respectively [41, 42]. Light-inducible circuits in E. coli have been constructed by creating chimeric fusions of phytochromes and histidine kinases as well as by heterologously expressing cyanobacterial two-component systems [43, 44]. Bioinformatics has enabled the expansion of this set of parts via genomic mining of novel transcription factors in 
prokaryotic genomes [45]. Other small-molecule-inducible systems developed over the past decade include the propionate-inducible PrpR system, the rhamnose-inducible RhaRS system, the cumate-inducible cym / cmt system from Pseudomonas putida F1, and the toluate or benzoate-inducible xylS system from $P$. putida [46-49]. Recent work by Rogers et al. focused on expanding this toolkit by characterizing the dynamics, host toxicity, and orthogonality of AcuR, an acrylate-inducible catabolism regulator in Rhodobacter sphaeroides, CdaR, a glucarate-inducible transcriptional activator, MphR, a macrolide-responsive transcription factor, and $\operatorname{TtgR}$, a flavonoid-responsive efflux pump regulator in P. putida [50]. The continued addition of new ligand-inducible transcription factors to the synthetic biology toolbox will help expand the range of practical applications that can be addressed by the field.

In eukaryotic systems, early inducible systems often involved the construction of chimeric proteins, such as those composed of a hormone-binding domain, the DNAbinding-domain of the Gal4 protein from yeast, and a transactivating domain from herpes simplex virus protein VP16. These inducible systems function via hormone-induced translocation into the nucleus, which allows Gal4 to bind to its cognate site and activate transcription [51-54]. Another system consists of small-molecule inducible bacterial transcription factors fused to eukaryotic transactivation or transrepression (e.g., KRAB from the human kox-1 gene) domains. The bacterial portion of these chimeric proteins are derived from antibiotic-resistance machinery (e.g., the pristinamycin-resistance system of Streptomyces pristinaespiralis and the tetracycline-resistance and erythromycinresistance systems from E. coli); in the presence of antibiotic, the protein and the allosteric effector form a complex resulting in a change of affinity of the DNA-binding do- 
main for its DNA target [55-57]. Recent innovations in expanding the diversity of inputs available for inducible circuits have further exploited bacterial-mammalian chimeric proteins. For instance, Gitzinger et al. utilized the flavonoid-responsive TtgR operon from Pseudomonas putida to build a mammalian system responsive to phloretin, a component of some cosmetics [58]; Wang et al. built a system responsive to paraben derivatives, a common ingredient of skin-care products, and demonstrated the ability of commercial cosmetics to induce expression from subcutaneously implanted engineered cells [59]. In addition to yeast-derived and bacteria-derived systems, humancomponent-based inducible systems have been constructed that function via rapamycin-inducible assembly of a synthetic transcription factor; such systems are thought to have a reduced risk of undesired immunogenicity in a gene therapy context [60]. Over the past decade, the eukaryotic ligand-inducible transcription factor toolkit has rapidly expanded to include expression systems that can be controlled via quorum-sensing (QS) signal molecules, NADH, L-arginine, biotin, and more [61]. In addition to harvesting parts from nature, the continuing development of computational design methods and large-scale mutagenesis and screening techniques may expedite the construction of new "designer" allosteric transcription factors via the rational re-design of wellcharacterized transcription factors to recognize related, yet distinct, novel ligands [62].

Synthetic transcription factors based on DNA-binding domains, such as zinc finger nucleases (ZFNs), transcriptional activator-like effectors (TALEs), and the CRISPR (Clustered Regularly Interspaced Short Palindromic Repeats)/Cas system, fused with transcriptional effector domains have also been constructed [63-68]. Zinc finger transcription factors (ZF-TFs) rely on creating arrays of zinc finger protein domains where 
each domain individually binds to a specific $\sim 3$ bp DNA sequence, allowing userdesigned specificity $[69,70]$. The refinement of methods for assembling zinc finger arrays (e.g., through oligomerized pool engineering (OPEN) or context-dependent assembly (CoDA) [71, 72]) has enabled the large-scale development and characterization of zinc-finger based transcription factors [63]. By placing ZF-TFs downstream of wellcharacterized endogenous promoters, it is furthermore possible to couple natural sensing machinery capable of detecting hypoxia and DNA damage with synthetic actuators composed of transcriptional ZF-TF circuits for sensing and reporting internal cell states [73].

Another approach to constructing synthetic TFs relies on transcription activatorlike effector (TALE) proteins from Xanthomonas spp. that consist of tandem arrays of 33-35 amino acid domains with each domain binding to a single nucleobase. Arrays of TALE domains can be linked together to engineer binding to user-specified sites $[74$, 75]. Combinations of TALE-TFs can be employed to further fine-tune engineered regulatory transfer functions [64]. By swapping out the transcriptional effector domain for epigenetic effector domains (e.g., the LSD1 histone demethylase domain or the TET1 hydroxylase domain which enables DNA demethylation), researchers have also demonstrated the utility of TALEs for efficient epigenome editing $[76,77]$. In comparison to TALEs, ZF-TFs can be more difficult to design and suffer from a higher failure rate [78]; however, their smaller size and less repetitive coding sequences may be beneficial for delivery in a therapeutic setting.

The most recent advance in synthetic transcriptional regulation has emerged from the adaptation of prokaryotic CRISPR/Cas immune system. In its most commonly 
used form, the CRISPR system consists of the Cas9 protein (an RNA-guided nuclease) and associated guide RNAs, which target Cas9 to specified regions of the genome [79]. Given its advantages over TALEs and ZF-TFs (including the ease of design and the ability to "multiplex" outputs), the CRISPR system with a catalytically inactive Cas9 (dCas9) fused to either activator or repressor domains has been widely applied to regulate the transcription of synthetic and endogenous genes in both prokaryotic and eukaryotic systems [65, 80-82]. Cas9 can further be engineered to detect small-molecule inputs via the incorporation of ligand-responsive inteins or rapamycin-inducible dimerization [83, 84]. By integrating RNA-level elements for stability and recruitment of RNAbinding transcriptional effectors, synthetic biologists have expanded the capacity of the CRISPR system to support multistage and multicomponent genetic circuits [85-87]. Furthermore, Kiani et al. demonstrated that RNA-DNA base pairing properties of the CRISPR guide RNAs can be exploited to allow simultaneous genome editing and transcriptional regulation with the basic Cas9 system, further adding to the versatility of this system [88]. Optogenetic control over the CRISPR system has been demonstrated via incorporation of the Arabidopsis thaliana CRY2 \& CIB1 system [89, 90]; similar work had previously been conducted using the same CRY2 \& CIB1 system to enable lightinducible engineered TALEs to modulate gene expression [91]. CRISPR, TALE, and ZF platforms will furthermore likely continue to play a pivotal role in the development of tools for editing and regulation at genetic and epigenetic levels [91-96].

RNA-based components have also been developed which, through various mechanisms, can activate or attenuate transcription and furthermore enable the creation of RNA-only circuitry [97-100]. This can, in turn, open up new methods of incorpo- 
rating inputs into circuits. For instance, Hoynes-O'Connor recently demonstrated the denovo design of RNA thermosensors in E. coli; under high temperatures, an RNase E cleavage site on the mRNA of interest is exposed and leads to mRNA cleavage and the loss of expression [101]. Prior thermosensitive circuits relied on protein control via a mutant form of the $\mathrm{cl}$ repressor from the well-studied lambda bacteriophage, which results in de-repression at $42^{\circ} \mathrm{C}[1,102]$. Additional control can be derived from tuning posttranscriptional RNA stability, by suppressing specific mRNA molecules through RNA interference in eukaryotes, and through synthetic small non-coding RNAs (sRNAs) in prokaryotes [103, 104]. Important for the development of these parts are computational models; for instance, aptazymes and ribozymes enable transcript degradation in a predictable and robust manner and can therefore be designed using kinetic RNA folding simulations [105]. For a thorough review of RNA-specific synthetic biology tools, see Chappell et al. [106].

Translational control via RNA engineering serves as yet another vital point of control for synthetic biologists. Modulation of the strength of translation via replacement and mutation of the ribosome-binding sequence (RBS) in bacteria has long been a popular mode of tuning protein expression levels. These efforts have been aided by statistical thermodynamic models of RBS efficacy that can predict protein coding sequence translation rate over a 100,000 fold range $[107,108]$. RNA devices such as the riboregulator, consisting of a cis-repressed mRNA that prevents translation via a stemloop structure and a trans-activating RNA that hybridizes with the stem-loop and exposes the RBS, as well as the similar RNA-IN-RNA-OUT system, which inducibly blocks ribosome access to the RBS via antisense stem-loop RNA expression, have allowed for 
additional control over translation initiation and timing $[109,110]$. Green et al. expanded on the conventional riboregulator approach but instead utilized linear-linear RNA interactions to create toehold switches that have allowed for regulation of translation over a 400-fold dynamic range, which is on the order of protein-based regulation [111]. The dynamic range of toehold switches, as well as their ability to be multiplexed due to limited crosstalk, makes them attractive candidates for applications integrating biosensing and computing. Coupling toehold switches with the tna element adaptor (as Liu et al. did with the RNA-IN-RNA-OUT system [98]) could furthermore allow for straightforward composition of wide-dynamic-range toeholds into diverse transcriptional regulatory functions .

Engineering the genetic code of translation is a nascent area of synthetic biology tool development. Expansions of the genetic code require an "open" codon and (ideally orthogonal) machinery (i.e., aminoacyl-tRNA synthetase and tRNAs with elongation factors and ribosomal machinery) capable of incorporating noncanonical amino acids [112, 113]. In an effort to more systematically address the initial hurdle of freeing up codons for usage, Lajoie et al. demonstrated that $E$. coli can be genomically recoded via the replacement of all known UAG stop codons with UAA stop codons, allowing for increased bacteriophage resistance and the ability to incorporate non-standard amino acids [114]. The incorporation of noncanonical amino acids has a myriad of applications, including, for instance, alternative methods to confer photoregulation of biological processes (in both bacterial and mammalian systems), biocontainment of GMOs via engineered dependence on non-standard amino acids, modification of therapeutic proteins for increasing substrate affinity or affecting pharmacokinetic features, and more [115-120]. How- 
ever, challenges still remain including fitness impairments in recoded genes and generally lower efficiency of translation with noncanonical amino acids [112, 121]; for a thorough overview of the field and outstanding challenges, see Lajoie et al. [122].

The development of novel orthogonal components of translation has also contributed numerous well-characterized parts to the synthetic biologist's toolkit. Approaches to creating orthogonal translation systems have focused on evolving 16S rRNA variants (which recognize different Shine-Dalgarno sequences) and 23S rRNA variants (via alteration of the peptidyl transferase center) [123-125], as well as evolving ribosomes to recognize quadruplet codons $[126,127]$. More recently, Orelle et al. created an "artificial" ribosome (called Ribo-T) comprising tethered subunits capable of replacing the endogenous system in E. coli and engineered to be orthogonal using a Shine-Dalgarno sequence variant [128]. Directed evolution techniques can be used to further refine the orthogonality of the various components of these translation systems [129].

Post-translational control, such as protein degradation, can also be inducibly activated in both prokaryotic and eukaryotic systems [130-132]. Recent work by Cameron \& Collins demonstrates the benefits of utilizing an inducible Lon protease system from Mesoplasma florum in E. coli, which degrades tmRNA-tagged substrates; such a system is both tunable and a useful tool for the systematic perturbation of natural protein networks [133]. For a review of recent developments in the post-translational toolkit, see Olson \& Tabor [134].

\section{Circuit characterization \& tuning}


Novel DNA assembly techniques (e.g., the Golden Gate method and Gibson assembly as well as genome engineering technologies such as conjugative assembly genome engineering) have greatly reduced the time spent in the construction phase of the synthetic circuit or synthetic genome engineering cycle [135-138]. However, there still exists a need for higher-throughput and novel methods for characterizing genetic parts and circuits. Conventionally, part and circuit characterization relies on assessing parameters such as the fold change and time course of a fluorescent protein output from an upstream synthetic component. The data from these characterization experiments can be recorded in a datasheet format, which provides a quantitative description of the behavior of a part. The Registry of Standard Biological Parts, now over a decade old, seeks to store information on characterized parts and now contains over 20,000 documented entries [139].

A core component of such datasheets is the characterization of the transfer function, which maps the range of input levels (e.g., concentrations of small molecules or intensity of light) to a range of output levels at steady state; empirical transfer functions guide how synthetic biologists characterize and optimize circuit performance. For instance, for components of digital logic circuits (e.g., computing on binary signals), a sharp transfer function is often desired (see Fig. 1b) whereas for applications of analog computing (e.g., computing on continuous values) a wide-ranged transfer function quantitatively described by a linear or log-linear relationship may be more appropriate (see Fig. 1f). Furthermore, the process of composing genetic parts for higher-order synthetic systems necessitates that the output range of one circuit fits well with the input range of another. Similar to the problems that arise from improper impedance matching in elec- 
tronics, improperly layered circuits will suffer from deviations from expected behavior [140].

The incorporation of optogenetics as a means to interrogate synthetic circuits can help expand circuit characterization from the static perspective of a transfer function to a dynamic perspective of its behavior through time. For instance, Olson et al. recently proposed an optogenetics-based gene circuit characterization method utilizing lightinducible two-component systems (comprising light-inducible kinases and paired transcriptional response regulators); they applied their system to better understand the dynamical properties of synthetic inverter circuits given analog light inputs [141]. In contrast to typically used small-molecule-based characterization methodologies, employing phytochrome-family light-responsive proteins leverages the ease of creating multiplexed light inputs to control biological circuits. This biological "function generator" enabled OIson et al. to create a dynamical model of the system parameterized by experimental data, which was then used to design custom protein-expression dynamics by iteratively adjusting the light input to minimize the error (i.e., the difference between predicted and desired expression levels) [141]. The continued development of these and other dynamical circuit characterization methods (an overview is given by Castillo-Hair [142]) complement the static picture of circuit behavior provided by empirical transfer functions. To fully characterize a part may also require explicit consideration of any contextdependent effects that might arise from functional couplings at element-element junctions (see section on "Modularity" for greater detail). Mutalik et al. worked to address this by employing a statistical ANOVA-based framework for assessing part "quality," a metric which should help give circuit designers an impression of how well a given part 
performs in different contexts and where troubleshooting efforts may be best applied [143].

All characterization approaches will likely benefit from the greater integration of high-throughput characterization techniques such as microfluidics and flow cytometry into the engineering process [144-146]. Automation of key steps in the cytometry pipeline (e.g., [147]) as well as the continued automation of laboratory techniques in general through robotics represent welcome steps towards a streamlined, computer-aided and machine-automated design process for building synthetic biological systems. Fully realizing this goal will require both data standards for communicating designs (e.g., the Synthetic Biology Open Language) and software to assist with the design and interpretation process [148-150].

It is important to note that current efforts to construct circuits with desired behaviors almost always require some fine-tuning of the various biological components. Such fine-tuning might include altering or swapping promoters via mutations, changing plasmid copy number, mutagenizing translational control elements, introducing DNA looping to enhance cooperativity, adding operator positions or any combinations thereof [140]. Alternatively, in contrast to precise rational design, some synthetic biologists have opted to use directed evolution to evolve desired circuits and parts [151, 152]. Mathematical models can be employed to guide the design and troubleshooting process, though challenges still remain for the development of reliable predictive models [153, 154].

\section{Modularity}


Modularity, which refers to the ability of parts to achieve context-independent performance and to be combined together without undesirable interactions, has long been a desired goal of synthetic biologists. Systems found in nature sometimes exhibit a surprising degree of modularity; for instance, the modularity of the mitogen-activated protein (MAP) kinase pathway has been utilized to rewire signaling dynamics and introduce new inputs into the natural MAPK pathway $[155,156]$. In viruses, synthetic biologists have taken advantage of relatively modular capsid components to create synthetic phages with altered host ranges [157]. Engineered DNA binding proteins, like TALEs, are often employed in synthetic circuit construction precisely because of their modular nature [158].

Despite these examples, the majority of synthetic parts and circuits do not exhibit ideal levels of modularity. At the level of transcription, context-dependent effects can arise, for instance, from the presence of cis-regulatory elements or from RNA interactions between the 5' UTR and the nascent mRNA, which can affect the initiation of translation [108]. Early work to mitigate the effects of these interactions focused on the rational design of promoters with well-defined upstream and downstream components [159]. Another approach focuses on the inclusion of RNA processing machinery (e.g., either the autocatalytic ribozyme RiboJ or the CRISPR-associated endoribonuclease Csy4), which enables modularity by cleavage and removal of the 5'-UTR from nascent mRNA [160, 161].

At the level of translation, it is now well recognized that a given bacterial RBS element is coding-sequence-dependent and can result in varying output levels based on the specified genetic context [108]. To address this, Mutalik et al. created a set of trans- 
lational insulator elements based off of bacterial "coupled translation" systems composed of overlapping upstream coding regions and downstream RBS regions [162, 163]. In their system, this bicistronic design (BCD) for translation initiation (which significantly reduced GOI-dependent translational variance) was further coupled with a standardized transcription library with defined 5'-UTRs to achieve more predictable gene expression [164].

At the level of protein engineering, even the oft-cited modular nature of zincfinger arrays was brought into question when Ramirez et al. demonstrated a $\sim 76 \%$ failure rate of modular assembly for a particular class of target site [165]. Mitigating this particular mode of failure might necessitate switching to other more modular DNAbinding systems (e.g., TALEs or CRISPR) due to the difficulty of tuning and troubleshooting zinc-finger array assembly.

Addressing context-dependence at the parts level will expedite the design process. However, to design and construct synthetic systems composed of layered genetic sub-modules will require a better understanding of modularity at the circuit level. Recent work by Mishra et al. sought to address this challenge via the inclusion of a synthetic "load driver" comprising a phosphotransfer cascade in between the input and the output (downstream genes) of a genetic circuit [166]. Mishra et al. demonstrated that inclusion of their system significantly decreases system response time and bandwidth in a circuit undergoing substantial load. Further exploration of modularity, insulation, and current efforts to address these issues can be found in a recent review [167].

\section{Host Effects}


Closely related to the pursuit of modularity is better understanding and addressing the burden, or the over-utilization of shared resources, that synthetic heterologous systems impart on their hosts, which can often produce surprising results in circuit behavior [168, 169]. Mathematical models of cell growth and its effect on gene expression as a result of the availability of cellular resources have been constructed to assist with genetic circuit design [170-172]. Better methods for characterizing host-burden will be needed; often, circuit burden has largely been characterized through simple measurements of growth dynamics in cells with and without the synthetic circuit. Ceroni et al. have recently sought to address this with the development of a 'capacity monitor' consisting of genomically-integrated constitutive GFP as a proxy for resource availability [173]. For a small library of simple circuits, the authors found that capacity and growth rate correlated strongly but inversely so with output of the circuit. Model-driven analysis then allowed them to select and characterize the difference between two circuits with similar outputs but varying capacity levels. Incorporation of synthetic parts or circuits specifically designed to reduce host-burden may be another way to address the challenge. For instance, using transposons, Segall-Shapiro et al. constructed a fragmented T7 RNA polymerase where expression of all subunits is necessary to activate downstream synthetic circuits. Subunits comprise a core fragment that determines the total amount of "cellular resources" available to be allocated among multiple " $\sigma$ fragments", which enable binding to different promoters [174]. The authors successfully demonstrated that such a partitioning can be harnessed to coordinate and tune expression levels to decrease toxicity. However, constructing split proteins for usage in other circuits may prove to be more challenging. 
Efficiently adapting genetic circuits that function well in one host to a different one is currently a topic of great interest within the community, which, if able to be conducted routinely, would allow for rapid prototyping of circuits in model strains before porting of the system over to more specialized chassis [175-177]. In addition to employing new characterization techniques, higher-complexity synthetic circuits may be able to compensate for host-dependent effects. For instance, Kushwaha et al. employed mixed feedback loops to enable self-regulation of the expression of heterologous transcriptional machinery, though the system was limited to bacterial hosts [178]. A thorough understanding of host-effects of heterologous circuits will be broadly useful for any application of synthetic biology, ranging from fitness considerations of engineered gut bacteria in the gut to optimization of small-molecule production in bioreactors.

\section{Digital \& Analog Computing}

In synthetic biology, abstracted mathematical models of the desired input-output transfer functions are realized through the design and implementation of synthetic gene circuits. Molecular components are synthetically 'wired' together to comprise a genetic circuit that can realize the desired input/output response. Inspired by the discipline of electrical engineering, a growing group of circuit designers have sought to create digital circuits and analog circuits for computing applications. In the digital logic paradigm, biochemical signals that serve as inputs and outputs, such as concentrations, intensities, etc., are arbitrarily categorized to represent 'ON' ('1' or 'High') and 'OFF' ('O' or 'Low') states. By building simple switch devices that switch between the 'ON' and 'OFF' states and by interconnecting multiple such devices, complex computation can be achieved. In 
the analog paradigm however, the whole range of concentrations/intensities of the input/output signals is used for computation (see Fig. 1 for a comparison of the two approaches). Computation within the analog paradigm is performed by implementing abstracted mathematical functions based on the biochemical and biophysical laws governing the properties of the interacting molecular components. Unlike in the digital logic paradigm, complex computation can often be realized by far fewer molecular components. For further in-depth information, please refer to additional reviews [179-182].

\section{Digital synthetic gene circuits}

Over the past couple of decades, there have been a wide variety of synthetic digital logic circuits implemented at the DNA, RNA and the protein level, across both prokaryotic and eukaryotic hosts. While building digital synthetic gene circuits, regardless of the underlying biological implementation, one has to bear in the mind the challenge of achieving steep input-output transfer functions to result in digital responses. Techniques often employed to tune transfer functions to exhibit digital behavior often involve exploiting positive cooperativity and positive feedback loops $[63,183]$.

One of the first synthetic gene circuits built was a toggle switch in E. coli that employed two mutually repressing genes to inhibit the expression of one other, resulting in a bi-stable memory circuit [1]. The state attained and maintained by the toggle switch system can be switched by adding small molecule inducers that regulate the activity of

the genes involved. Several variations of the bi-stable circuit have been built and tested since then [183-189]. An alternative approach that has been developed to maintain sta- 
ble states within cells is by changing the configuration of intracellular synthetic DNA. This can be accomplished using enzymes known as recombinases that are capable of flipping the DNA present between att ('attachment' sites) [190-196].

Digital circuits capable of complex computation have been built by combining simple memory switches. Counters that can count up to three input pulses were built using recombinase based Single Invertase Memory Modules (SIMMs) [193]. Using the unidirectional recombinases Bxbl and phiC31, Siuti el al., [195] built all of the 16 possible 2-input Boolean logic gates. Using a similar approach, Bonnet et al., [197] built logic gates implementing the digital functions AND, NAND, etc. A large number of logic gates have been created at the transcriptional level by employing synthetic transcription factors that are built by fusing transcriptional effectors (VP16, p65, KRAB, etc) with DNA binding domains (TetR, Lacl, Zinc fingers, TALENs and CRISPR-Cas). By using the combined action of gene activation and repression, Kramer et al. [198] built NOT IF-, AND-, NOT IF IF-, NAND-, OR-, NOR-, and INVERTER-type logic gates. More recently, CRISPR-Cas based digital logic gates that have a high potential for scalability have been proposed [199], although achieving high cooperativity and sharp transfer functions may be challenging. In addition to building logic gates at the transcriptional level, RNA interference (RNAi) has been leveraged to build logic gates in mammalian cells [200, 201]. A miRNA-profile based classifier that can distinguish HeLa cells from HEK 293T cells was built by layering multiple RNAi based logic gates in a multi-input fashion [202]. Furthermore, additional RNA based logic can be enabled by synthetic ribozymes and ribo-switches that trigger catalytic RNA cleavage in a programmable fashion [203, 204]. Approaches have been developed to build synthetic switch circuits at the protein level 
which operate at faster time scales compared with their transcriptional and RNA-based counterparts [156, 205].

By interconnecting multiple digital logic gates, Auslander et al., [4] built a complex, half-adder circuit that can add two digital logic bits together. Larger, multi-input logic gates, such as a 4-input AND gate, have been built by inter-connecting smaller, 2 and 3-input AND gates within individual cells [206]. The approach of interconnecting logic gates into higher-order computation has also leveraged inter-cellular communication enabled by quorum-sensing systems. For instance, Tabor et al. combined a sensor circuit, a quorum-sensing system, and an X AND (NOT Y) gate (where X represents AHLbound activator LuxR and $\mathrm{Y}$ represents the cl repressor) to achieve spatial signal processing capabilities in living cells [207]. Inter-communicating cell populations implementing different logic gates were combined to construct all of the possible 162 -input logic gates, 2-1 multiplexers and half-adders $[3,208]$.

\section{Analog synthetic gene circuits}

Due to the limited availability of cellular resources, the complexity of digital synthetic gene circuits can be hard to scale to perform higher-order calculations. Analog synthetic gene circuits provide an alternative design paradigm that enables implementation of complex computation using the underlying mathematical principles of biochemical processes within cells. Analog synthetic gene circuits can be useful when one desires graded responses to environmental signals such as those found in nature. However, the rational design and implementation of analog synthetic gene circuits is relatively new in 
the field of synthetic biology.

By expressing the transcription factor, TetR, in a negative auto-regulatory feedback loop, Nevozhay et al., [211] linearized the dose-response curve to widen the inputoutput dynamic range from a typical Hill-type response common in synthetic gene circuits implementing digital logic. Daniel et al., built analog synthetic gene circuits that exhibit log-linear behavior over an input dynamic range of four orders of magnitude (see Fig. 1) [212]. Using the wide log-linear transfer function, the authors implemented subtraction and division operations amongst the inputs. Moreover, the authors also built a feedback circuit, which implements a power-law relationship between the input and the output.

Hybrid circuits that incorporate both digital and analog processing have also been described. While operating in the digital paradigm, one is usually limited by the number of possible states that can be specified using distinct small molecules. A hybrid, digital-to-analog (DAC) converter can help overcome this limitation by specifying different output levels as a combinatorial combination of the distinct input chemical species, thereby scaling the maximum number of cell states that can be specified [213]. A prototypical DAC was built by Siuti et al., [214] wherein multiple recombinases expressed by distinct inputs independently turn 'ON' the expression of the same output gene driven by different constitutive promoters. By using constitutive promoters of different strength, different levels of the output gene were achieved by the combinatorial combination of the inputs. A different approach to digital-to-analog computation employs digital processing on a single-cell level (i.e., a given cell is individually either 'ON' or 'OFF') but analog processing on the population level (i.e., the fraction of cells in a population that is 
'ON' enables continuous memory and logic due to the large population sizes of bacteria). Farzadfard and Lu constructed such a system by combining the ssDNA-mediated recombination system of bacteriophage $\lambda$ with an ssDNA-expression cassette to enable inducible genomic recording of the magnitude and temporal dynamics of chemical and light inputs [215].

\section{Systems Biology}

The relationship between systems biology and synthetic biology has often been described as synergistic: insights from natural networks provide parts and modules for synthetic biologists and synthetic circuits, in turn, are built to rigorously test our models of natural systems. One area where this complementarity is most evident is in the investigation of biological networks, where the "forward-engineering" perspective of synthetic biologists has been both inspired by and a contributor to studies of natural motifs. Models incorporating circuit architecture \& exploring alternate topologies often lead to novel insights into the robustness of natural biological networks $[216,217]$. Synthetic circuits can offer a means to test these models. For instance, Çağatay et al. investigated the $B$. subtilis competence circuit using a synthetic variant wherein the native negative feedback circuit consisted of expression of an inhibitor (MecA) instead of repression of an activator (ComS), as is present in the wild-type strain [218]. This enabled researchers to compare functional differences in competence dynamics arising due to variation in circuit topology. In comparison to the synthetic version, the natural system exhibited greater variability in competence duration times, thought to be advantageous in an unpredictable environmental context [218]. A better understanding of the effects of positive 
and negative feedback topologies can then, in turn, allows bioengineers to exert greater degrees of control over the shape of circuit transfer functions. For example, it is now clear that appropriately tuned negative feedback loops can yield behavior including faster response times, dynamic-range increases, and a linearization of the transfer function for a TetR system, all of which are potentially attractive features for gene expression or biosensing applications $[211,219,220]$.

A subset of systems biologists have focused in particular on studying network motifs which occur more often than expected and thus are thought to carry specific information-processing capabilities; for instance, depending on the particular configuration, the feed-forward loop (FFL) can act to create sign-sensitive delays or as a pulser $[221,222]$. Early work in synthetic biology often involved the direct construction of these motifs in order to recapitulate predicted behavior, often in conjunction with mathematical modeling. For instance, Entus et al. used a simple model of the Type-l incoherent feedforward loop (I1-FFL) to predict the effect of mutations (represented by variations of key parameters) on the transfer function of their circuit and verified their predictions experimentally [223]. Incorporation of basic network motifs into larger circuits allows for more complicated processing capabilities; Basu et al. integrated a synthetic I1-FFL circuit with a quorum sensing (QS) circuit to enable population-level sensing and pulse-generation [224]. In these early years of synthetic biology, the "build to understand," forward engineering perspective (see Fig. 2a) complemented studies to understand naturally occurring instances of these circuits (e.g., $[225,226])$ and taken together, conferred a broader, more holistic understanding of the function of these motifs [227]. 
Synthetic biologists have complemented the "build to understand" approach with the "build to demonstrate" approach, where well-characterized motifs are used as test beds for implementing engineering concepts such as orthogonality or model-based design. For instance, An and Chin created an orthogonal expression system composed of an orthogonal ribosome and mRNA pair coupled with T7 RNAP, and arrayed their network in a FFL topology to demonstrate the ability to mediate tunable delays for orthogonal protein production [228]. Ellis et al. created a library of genetic components and with modeling, constructed various FFLs in a "plug-and-play" nature [153]. The close alignment of experimental results and model predictions the authors found is, however, not yet routine in synthetic biology and further work will be necessary to understand where predictability breaks down.

Oscillatory behavior and its mathematical analysis is another domain of interest for systems-level biologists. Focus is given to not only the composition and description of the various submodules of an oscillator but also its emergent behavior, characterized by its metrics such as its robustness and periodicity [229]. Early efforts to study natural oscillators and construct synthetic ones centered on either the construction of dualfeedback circuits or a three-repressor system (see Fig. 2b) [2, 230, 231]. The addition of QS machinery further allowed for the creation of synchronized oscillations at the colony level [232, 233]. The applications are diverse: for instance, the construction of genetic clocks provides insights into what is needed for robust oscillatory behavior, a core component of many fundamental physicological and behavioral processes [234, 235]. Transplantation of genetic oscillators (e.g., the KaiABC cyanobacterial system) into other organisms can help elucidate core components necessary for recapitulating oscillato- 
ry behavior [236]. The opposite also holds true - heterologous expression of genes and circuits from other organisms can help elucidate core components behind oscillatory behavior in their native context. For instance, Pattanayak et al. expressed the galP sugar symporter from E. coli in cyanobacteria and demonstrated that rhythmic feeding synchronizes the endogenous KaiABC clock [237]. By rewiring the metabolism of cyanobacteria, Pattanayak et al. were able to demonstrate another avenue by which the cyanobacterial clock is synchronized. Understanding oscillatory behavior and constructing synthetic oscillators can have broad applications: for instance, synthetic oscillators controlling metabolic pathways may be needed to fine-tune the growth of engineered microbial consortia, as studies of $B$. subtilis biofilm communities suggest [238]. Furthermore, synthetic oscillators may someday be applied to correct the loss of microbiota oscillations and the resulting detrimental effects on human health (e.g., dysbiosis from chronic jet lag) [239]. A more comprehensive overview of synthetic genetic oscillators from mathematical, computational, and biological perspectives can be found in Purcell et al. [240].

Perspectives and approaches derived from control theory have likewise influenced both systems and synthetic biologists. In particular, frequency domain analysis has been used to understand phenomena ranging from simple genetic circuits to osmoadaptation in yeast [241-243]. Furthermore, in light of growing recognition of homeostasis as a control circuit, with disease as a consequence of its disruption [244], synthetic biologists have designed control-theory-inspired circuits to correct physiological imbalances. For instance, Kemmer et al. engineered a mammalian circuit to detect and correct imbalances in uric acid levels and demonstrated that their system worked as effec- 
tively as standard drug therapy in urate deficient mice [245]. Rossger et al. coupled a fatty acid sensor with the production of pramlintide, a peptide hormone which suppresses appetite, and demonstrated that compared to wild-type mice, obese mice implanted with this synthetic circuit exhibited lower levels of food consumption, blood fat levels, and body weight under a high fat diet [246]. These and other examples (e.g., [247, 248]) demonstrate the immense therapeutic potential of synthetic control circuits.

Finally, the DNA assembly strategies developed for synthetic biology applications can be useful for deciphering complex natural networks, which are often combinatorial and intertwined. For example, barcoded genetic perturbation libraries that target individual genes can be rapidly assembled in pooled format into high-order combinatorial genetic perturbation libraries that simultaneously overexpress or downregulate genetic combinations (e.g., 2-wise, 3-wise, and higher order sets of genes). Tracking the enrichment and deprivation of such barcodes in pooled populations with next-generation sequencing enables the rapid mapping of combinatorial genetic interactions in microbial and human systems [249-252].

\section{Metabolic Engineering}

The overlap between the fields of metabolic engineering and synthetic biology continues to grow. Conventionally, metabolic engineering has focused on improving product titer, yield and productivity through the tuning of metabolic flux or the introduction of heterologous genes; this systems-focused, industrial perspective might be thought to differentiate metabolic engineering from synthetic biology [253]. However, as Nielsen \& Keasling note, for many applications today in industrial biology, a synergistic platform 
integrating both metabolic engineering and synthetic biology approaches (the latter enabling environmentally responsive circuits and self-regulation to enhance performance and reduce toxicity) may be required (see Fig. 3) [254]. Applications of synthetic biology in a therapeutic context will likewise increasingly integrate tools of metabolic engineering; for instance, synthetic biologists interested in engineering the microbiome to inducibly produce therapeutic small molecules or degrade toxic metabolites will depend heavily on pathway optimization and the suite of tools metabolic engineers have developed to address this challenge. We briefly review examples of engineering at the intersection of these two fields with a particular focus on circuits and genome-engineering tools that have been developed to enable more dynamic and high-throughput approaches to metabolic engineering. As the diversity and complexity of small molecules of interest to bioengineers continues to grow along with the need for dynamic control, we expect to see further synergistic overlap between the two fields.

Growing recognition of the role gene expression dynamics play in affecting metabolite production has led to the development of models in E. coli and yeast expanding traditional constraint-based frameworks (e.g., flux-balance analysis) with timedependent constraints (representing transcriptional regulation) (see Fig. 3c) [255-257]. Incorporation of transcriptional dynamics has enabled finer tuning of flux profiles by suggesting optimal times for activation or repression of a given metabolic pathway over the time course of a batch culture as opposed to a reliance on ab initio gene knockouts. This "ON-OFF" approach to optimizing production may be important when gene knockouts to increase yield cause notable growth impairment, decreasing productivity. Anesiadis et al. explored this approach for ethanol production in E. coli by utilizing a QS mod- 
ule for density-dependent repression (via a toggle switch) of phosphotransacetylase (pta), which leads to inactivation of a competing acetate-production pathway [258]. Their synthetic circuit increased productivity but decreased yield and differed in behavior from predictive models that did not account for the timescale of repression and protein degradation [259]; nonetheless, their work highlights the impact synthetic biology can have on actualizing dynamic approaches to metabolic engineering. By further employing, for instance, CRISPR-based transcriptional regulation [20], one could conceivably achieve multiplexed regulation at many genomic loci on differing timescales.

Synthetic circuits have also been applied to mitigate deleterious host-effects due to the toxicity of intermediates. Zhang et al. engineered a control system comprising an engineered fatty acid/acyl-CoA sensor (FadR) to regulate the production of fatty acid ethyl ester (FAEE), a biofuel [260]. FAEE is synthesized by the enzyme wax-ester synthase using substrates ethanol and fatty acyl-CoA; both ethanol production and waxester synthase synthesis are inhibited by FadR in the absence of fatty acid. By reducing imbalances in the metabolic pathway, Zhang et al. were able to triple the yield of their strain. In situations where well-characterized sensors are not available, a systems biology approach can identify promoters responsive to toxic intermediate buildup that can then be strategically employed to reduce host burden [261]. These and other examples of synthetic circuits enabling dynamic control (see Venayak et al. for a recent review [262]) hold great potential for a more precise and robust approach for small molecule production.

Rational design and predictive models will, at times, fail to yield desired results due to gaps in our understanding of the complex temporal and spatial dynamics under- 
lying metabolic pathways. In such cases, metabolic engineers and synthetic biologists have opted to use directed evolution techniques consisting of iterative steps of mutagenesis, selection via screening, and amplification to enable the testing of large, combinatorial hypotheses for improving yield [263]. Directed evolution on the protein scale in recent years has benefitted from a range of innovations, including the usage of bacteriophage-based selection, RNA aptamers for coupling metabolite concentrations to fluorescence, and emulsion PCR-based amplification [152, 264, 265]. Genome engineers have expanded directed evolution approaches to multiple sites within the genome via the development of technologies such as multiplex-automated genome engineering (MAGE), which relies on incorporation of multiple single-strand oligonucleotides introduced via electroporation into daughter cell genomes [135, 266]. MAGE, coupled with co-selection, can reach incorporation efficiencies of greater than $70 \%$ and has been applied to increase, by four to fivefold, the production of lycopene as well as aromatic amino acid derivatives $[267,268]$.

It is important to note, however, that further development of directed evolution methods - even at the genome level - will be limited in throughput by downstream screening methodologies. For the applications of MAGE listed above, visual screens were utilized to assess intensity of pigmentation; this will not always be an available option for pathways of interest for metabolic engineers. The development of circuits comprising biosensors for metabolites coupled to fluorescent outputs can help address this. Fluorescent read-outs can easily be sorted in a high-throughput manner via fluorescence activated cell sorting (FACS). This mutagenesis combined with a FACS approach was used to select for higher productivity of amino acid synthesis in the industrial mi- 
crobe Corynebacterium glutamicum via circuits incorporating endogenous amino acidmediated regulatory devices for biosensing purposes [269, 270]. Endogenous machinery is often available and amenable for biosensor construction in situations where the metabolite of interest is core to the cell's survival. In situations where this is not the case, biosensors can be constructed by, for instance, engineering RNA switches comprising aptamer and output modules, engineering synthetic transcription factors (e.g., based off the CRISPR system), or by re-designing natural ones through high-throughput screening $[62,83,84,265]$.

\section{Towards Synthetic Ecosystems}

The assemblage of genetic parts into genetic circuits has dominated much of early synthetic biology efforts; more recently, there has been growing interest in higher-order systems composed of synthetic or engineered microbial and eukaryotic communities. Early examples of synthetic communities include engineered cooperation within yeast [271], a microbial predator-prey system utilizing killer or antidote genes and a QS system [272], tunable auxotrophic co-cultures [273, 274], and a QS based "band-detect" circuit capable of forming patterns [275] (see Kong et al. for additional examples [276]). Chen et al. recently demonstrated the construction of a consortium of two strains of $E$. coli capable of undergoing genetic oscillations only when mutually present via the coupling of two QS systems [277]. The development of synthetic communities may have implications for metabolic engineering; for instance, complex metabolites may be more amenable for multi-stage production using communities of engineered strains to offset the per-cell metabolic load. 
Despite these examples, there are still open questions and challenges in engineering communication between cells. In response, synthetic biologists have employed a "build to understand" approach, similar to the initial period of investigation into network motifs. For instance, the mechanisms by which cooperators coordinate and select against cheaters in bacterial quorums are still being elucidated. One emerging hypothesis is that QS machinery co-regulates both intracellular and extracellular enzyme production ("private" and "public" goods, respectively) and thus limits the cost of cooperation [278]. Zhang et al. investigated this possibility in $B$. subtilis by constructing a circuit composed of the heterologous Auto-Inducing-Peptide QS system which allows for sender-receiver communication but without affecting other aspects of the receiver's physiology [279]. Their results suggest that in comparison to the synthetic variant, wildtype strains demonstrate synergistic coupling of ECM production and quorum sensing which may, in turn, serve as a private good by allowing receiving cells to be more responsive to global cell density.

Engineering communication between cells remains challenging as natural QS sensing pathways often exhibit cross-talk and will require further tuning and characterization to achieve desired levels of modularity [280]. To understand this phenomenon, Wu et al. constructed circuits comprising combinations of auto-inducer, regulator, and promoter for LuxR/I and LasR/I QS systems, characterized cross-talk as either signalbased or promoter-based, and modeled the complex bimodal and trimodal stability regions that emerge due to cross-talk and host-circuit interactions [281].

With respect to human health, understanding and engineering the gut microbiome as an ecosystem of microbial species in particular holds high therapeutic potential; 
studies have implicated the effect the microbiome has on inflammatory bowel diseases, obesity, asthma, diabetes, neurological disorders, behavior, and the metabolism of drugs [282-288]. Engineered strains have already been constructed for usage as sensors to detect small molecule environmental stimuli in the mammalian gut [289]. Tools have begun to be developed for engineering species of gut bacteria already well-suited for colonizing the gut; these include members of the well-represented Bacteroidetes and Firmicutes [290, 291]. For instance, synthetic biologists have developed a toolkit amenable for engineering of the commensal Bacteroides thetaiotamicron comprising characterized promoters, RBS, inducible systems, and the CRISPRi platform [196]; similar work has begun to be conducted on members of the Firmicutes [292]. Synthetic biologists have also developed techniques for the targeted disruption of endogenous communities; for instance, modular viral scaffolds and phagemid-delivered CRISPR enable selective perturbation of bacterial communities $[157,293]$. These tools may allow for the targeted disruption of pathogens within the gut.

The further development of genetic circuits (e.g., cell counters) and imaging tools for gut flora will benefit in vivo efforts to study and understand host-microbiota interactions, interactions between species in the gut, and the dynamics of growth [294, 295]. Mathematical approaches to model the dynamics and evolutionary trajectories of synthetic ecologies will also be paramount; for an overview of current methodologies, see Zomorrodi \& Segrè [296].

\section{Challenges for the Future of Synthetic Biology}

In this review, we presented foundational synthetic biology engineering principles and 
highlighted in particular the intersection between synthetic circuits and the fields of digital \& analog logic, systems biology, and metabolic engineering. The creation of "nextgeneration" synthetic networks will likely necessitate the layering of these circuits into higher-order systems to achieve predictable behaviors at the organism and community scale. However, challenges remain for the forward-engineering of complex synthetic circuits:

1. As the field of synthetic biology matures, conceptual models for designing and understanding synthetic circuits and techniques for their construction and characterization will continue to diversify. Importantly, these models will become much more central to the synthetic-biology design cycle when they become predictive, which has been a major challenge thus far. Accurate quantification of various molecules involved in synthetic gene circuits, such as the precise numbers of proteins, plasmid DNA copy numbers, and mRNA numbers in single cells, could enhance the predictive power of circuit models. Towards this end, technologies including single-cell sequencing and newer developments such as fluorescent in situ sequencing (FISSEQ) may be helpful for synthetic biologists [297]. Coupling such gene expression data with metabolomics data (e.g., collected via mass spectrometry or NMR spectroscopy) could be important for metabolicengineering-related circuits or for obtaining a more complete perspective on the global impact of synthetic circuits [298, 299]. Detailed quantification strategies for synthetic circuits should help to determine what are the major determinants of success or failure in circuit performance, and lead to the development of ranking algorithms for comparing alternative circuit designs. 
2. The current design-build-test cycle is still slow and innovative methods are needed to automate construction, characterization, and tuning of parts and circuits. Employing robotic or acoustic liquid handling systems can help to reduce the repetitive manual labor that constrains the speed and scale of the current designbuild-test cycle and to minimize human error. Similarly, the increasing usage of microfluidics-based technologies can facilitate high-throughput characterization of circuit behaviors [144-146]. Machine-learning methodologies for incorporating findings from high-throughput experiments into quantitative design principles are needed.

3. Robust standardization of parts and data characterization is needed, especially for those components that cannot be characterized in a high-throughput fashion. This will enable the porting of parts across labs and building complex systems by combining simpler ones. In addition, strategies to determine and then mitigate undesirable interactions between parts and their host would enable greater portability of designs.

4. It is yet unclear if biological systems can achieve overall scalability via the design principles of modularity and orthogonality, as is the case with electronic devices. If this is not possible, alternative design principles that incorporate evolution, high-throughput circuit construction and screening, and non-digital computing, need to be explored and tested. A shift in paradigm from evolving stand-alone parts such as DNA binding proteins, promoter elements and enzymes of interest to evolving circuits and networks as a whole could be a powerful approach [152].

5. Finally, the goal of computation in biology is not towards artificial, general pur- 
pose computing but towards enabling sense and response behaviors relevant to biological applications. This realization should motivate a more application driven, top-down approach in designing synthetic gene circuits to tackle real-world challenges.

In summary, synthetic biologists have made significant progress over the last 15 years in establishing a broad suite of gene regulatory parts, assembling these parts together into higher-order circuits, widening the applicability of gene circuits into a range of prokaryotic and eukaryotic systems, and demonstrating proof-of-concept applications. We anticipate that expanding interest in the broad utility of synthetic biology to tackle difficult biomedical, industrial, and environmental problems will continue to drive growth in the pace, scale, reliability, and scope of synthetic gene circuit technologies that can be realized, but emphasize that synthetic biology remains a nascent field in which many fundamental challenges and opportunities remain to be solved. 


\section{Figure 1 | Conceptual models and characterization of digital versus}

\section{analog circuits}

(a) Schematic of a typical input-output transfer function, highlighting digital and analog regimes. When constructing digital synthetic gene circuits, synthetic biologists aim to achieve a steep transfer function and minimize the range of the 'analog' region. An analog synthetic gene circuit on the other hand has a more graded response with reduced step-like behavior (b-d) Dynamic switching between analog and digital synthetic gene circuit behavior. (b) Using a positive-feedback loop, Daniel et al. demonstrated dynamic adjustment of AHL-to-mCherry transfer functions between analog and digital behaviors using a CopyControl (CC) induction solution [212]. (c) To achieve dynamic behavior Daniel et al. used a variable-copy-number plasmid (VCP) which is normally maintained at low copy numbers but can be induced to higher copy numbers through CopyControlmediated expression of replication protein TrfA from a promoter integrated into the genome. (d) At high copy numbers (CC ON, red diamonds), the circuit behaves in a digital-like fashion. The dotted red line is a Hill function fitted to the digital-like curve. The dashed black line reveals that the digital-like curve is not well fitted by a $\ln (1+x)$ function. At low copy numbers (CC OFF, blue circles), the circuit behaves in an analog fashion with a wide dynamic range. The dashed blue line indicates that the analog-like curve is well fitted by a $\ln (1+x)$ function [212]. Figures $(\mathbf{b}-\mathbf{d})$ reprinted from Daniel et al. [212]. 


\section{Figure 2 | A "build to understand" approach to systems biology em- ploying synthetic circuits}

Forward engineering and in silico characterization of systems biology network motifs. (a) Type-I incoherent feed-forward loop (I1-FFL) motif, biological implementation (TF = transcription factor), and time-course for a simplified model of the I1-FFL [223]. The I1FFL exhibits pulse-generation and an accelerated response time (after normalizing with respect to steady-state output) $[221,222,224,225]$. For comparison, a TF2 mutant (TF2-Mut) which is unable to bind to and repress the output promoter is shown. (b) Synthetic oscillator ("repressilator") motif, biological implementation, and time-course. Repressilator schematic and time-course adapted from DNAplotlib and Elowitz \& Leibler [2]. Alternate oscillator topologies incorporating both positive and negative feedback have been explored in recent years [240]. Circuit diagrams drawn according to SBOL Visual specification; part-to-part arrows indicate activation and bars indicate inhibition. 


\section{Figure 3 | Complementing metabolic engineering with synthetic cir-}

\section{cuits for dynamic control}

(a) Synthetic circuits enable the dynamic correction of metabolite imbalances resulting in suboptimal flux, host toxicity, etc. A block diagram is used to illustrate this concept via a feedback loop where cellular information from the circuit input (e.g., a small-molecule inducer) and circuit biosensors is added at the summation point (e.g., through interactions of transcription factors) and results in expression of controller circuits that modulate metabolic processes. (b) An example of a dynamic controller by $\mathrm{Xu}$ et al. [300] where ACC represents the malonyl-CoA source pathway and FAS represents the malonyl-CoA sink pathway. The purpose of this circuit is to maintain requisite levels of malonyl-CoA for fatty acid production; excessive malonyl-CoA activates the sink pathway and insufficient malonyl-CoA results in activation of the source pathway. Behavior of the circuit is shown in (e). Figure reprinted from Xu et al. [300] (c) Left: static metabolic engineering using flux balance analysis to identify optimal mutants in the constrained solution space; blue and green dots represent two potential solutions along specific constraint boundaries (dotted lines) [301]. Right: a dynamic two-stage production strategy is instead utilized which allows for a time-dependent changing profile (dotted line connecting the two solutions) of an engineered strain (figure adapted from Venayak et al. [262]). (d) Metrics of interest for metabolic engineers include yield, the amount of product synthesized per the amount substrate, and titer, the amount of product per reaction volume. Biomass measurements are also important for understanding where yield and titers might be improved. Dynamically-regulated circuits (right) can sometimes achieve relatively higher yields or titers (in blue) but lower biomasses (in green) due to the host bur- 
den of synthetic circuits $[300,302]$. (e) Malonyl-CoA profile from strains without (left) and with (right) the controller circuit in (b). Dynamic regulation can lead to fluctuations in the time-course of small molecule production. Figure adapted from Xu et al. [300]. 


\section{Acknowledgements}

We thank members of the Lu laboratory for helpful discussions. This work was supported by the National Institutes of Health (DP2 OD008435, P50 GM098792), the Office of Naval Research (N00014-13-1-0424), and the National Science Foundation (MCB1350625). The project or effort depicted was or is also sponsored by the Defense Advanced Research Projects Agency (HR0011-15-C-0091). KCM acknowledges additional support from the Harvard College Research Program and the Harvard College PRISE. 


\section{REFERENCES:}

[1] Gardner TS, Cantor CR, Collins JJ. Construction of a genetic toggle switch in Escherichia coli. Nature. 2000;403:339-42.

[2] Elowitz MB, Leibler S. A synthetic oscillatory network of transcriptional regulators. Nature. 2000;403:335-8.

[3] Tamsir A, Tabor JJ, Voigt CA. Robust multicellular computing using genetically encoded NOR gates and chemical /'wires/'. Nature. 2011;469:212-5.

[4] Auslander S, Auslander D, Muller M, Wieland M, Fussenegger M. Programmable single-cell mammalian biocomputers. Nature. 2012;487:123-7.

[5] Belkin S. Microbial whole-cell sensing systems of environmental pollutants. Current opinion in microbiology. 2003;6:206-12.

[6] Daunert S, Barrett G, Feliciano JS, Shetty RS, Shrestha S, Smith-Spencer W. Genetically engineered whole-cell sensing systems: coupling biological recognition with reporter genes. Chemical reviews. 2000;100:2705-38.

[7] Tecon R, Van der Meer J. Bacterial Biosensors for Measuring Availability of Environmental Pollutants. Sensors. 2008;8:4062-80.

[8] van der Meer JR, Belkin S. Where microbiology meets microengineering: design and applications of reporter bacteria. Nature reviews Microbiology. 2010;8:511-22.

[9] Hua A, Gueune H, Cregut M, Thouand G, Durand MJ. Development of a bacterial bioassay for atrazine and cyanuric acid detection. Frontiers in microbiology. 2015;6:211.

[10] Martin-Betancor K, Rodea-Palomares I, Munoz-Martin MA, Leganes F, Fernandez-Pinas F. Construction of a self-luminescent cyanobacterial bioreporter that detects a broad range of bioavailable heavy metals in aquatic environments. Frontiers in microbiology. 2015;6:186.

[11] Moser F, Horwitz A, Chen J, Lim W, Voigt CA. Genetic sensor for strong methylating compounds. ACS Synth Biol. 2013;2:614-24.

[12] Reimer A, Yagur-Kroll S, Belkin S, Roy S, van der Meer JR. Escherchia coli ribose binding protein based bioreporters revisited. Scientific reports. 2014;4:5626.

[13] Wang B, Barahona M, Buck M. A modular cell-based biosensor using engineered genetic logic circuits to detect and integrate multiple environmental signals. Biosensors \& bioelectronics. 2013;40:368-76.

[14] Prindle A, Samayoa P, Razinkov I, Danino T, Tsimring LS, Hasty J. A sensing array of radically coupled genetic /'biopixels/'. Nature. 2012;481:39-44.

[15] Bi C, Su P, Müller J, Yeh Y-C, Chhabra SR, Beller HR, et al. Development of a broad-host synthetic biology toolbox for ralstonia eutropha and its application to engineering hydrocarbon biofuel production. Microbial cell factories. 2013;12:107. 
[16] Georgianna DR, Mayfield SP. Exploiting diversity and synthetic biology for the production of algal biofuels. Nature. 2012;488:329-35.

[17] Gimpel JA, Specht EA, Georgianna DR, Mayfield SP. Advances in microalgae engineering and synthetic biology applications for biofuel production. Current opinion in chemical biology. 2013;17:489-95.

[18] Peralta-Yahya PP, Zhang F, Del Cardayre SB, Keasling JD. Microbial engineering for the production of advanced biofuels. Nature. 2012;488:320-8.

[19] Rabinovitch-Deere CA, Oliver JW, Rodriguez GM, Atsumi S. Synthetic biology and metabolic engineering approaches to produce biofuels. Chemical reviews. 2013;113:4611-32.

[20] Cleto S, Jensen JK, Wendisch VF, Lu TK. Corynebacterium glutamicum metabolic engineering with CRISPR interference (CRISPRi). ACS synthetic biology. 2016.

[21] Chen YY, Smolke CD. From DNA to targeted therapeutics: bringing synthetic biology to the clinic. Science translational medicine. 2011;3:106ps42-ps42.

[22] Fischbach MA, Bluestone JA, Lim WA. Cell-based therapeutics: the next pillar of medicine. Science translational medicine. 2013;5:179ps7-ps7.

[23] Lienert F, Lohmueller JJ, Garg A, Silver PA. Synthetic biology in mammalian cells: next generation research tools and therapeutics. Nature Reviews Molecular Cell Biology. 2014;15:95-107.

[24] Planson A-G, Carbonell P, Grigoras I, Faulon J-L. A retrosynthetic biology approach to therapeutics: from conception to delivery. Current opinion in biotechnology. 2012;23:948-56.

[25] Weber W, Fussenegger M. Emerging biomedical applications of synthetic biology. Nature Reviews Genetics. 2012;13:21-35.

[26] Chang MC, Keasling JD. Production of isoprenoid pharmaceuticals by engineered microbes. Nature chemical biology. 2006;2:674-81.

[27] Keasling JD. Synthetic biology for synthetic chemistry. ACS chemical biology. 2008;3:6476.

[28] Paddon CJ, Keasling JD. Semi-synthetic artemisinin: a model for the use of synthetic biology in pharmaceutical development. Nature Reviews Microbiology. 2014;12:355-67.

[29] Chen AY, Deng Z, Billings AN, Seker UO, Lu MY, Citorik RJ, et al. Synthesis and patterning of tunable multiscale materials with engineered cells. Nature materials. 2014;13:515-23.

[30] Chen AY, Zhong C, Lu TK. Engineering Living Functional Materials. ACS synthetic biology. 2015;4:8-11.

[31] Fletcher JM, Boyle AL, Bruning M, Bartlett GJ, Vincent TL, Zaccai NR, et al. A basis set of de novo coiled-coil peptide oligomers for rational protein design and synthetic biology. ACS synthetic biology. 2012;1:240-50. 
[32] Jewett MC, Patolsky F. Nanobiotechnology: synthetic biology meets materials science. Current opinion in biotechnology. 2013;24:551-4.

[33] Rehm BH. Synthetic biology towards the synthesis of custom-made polysaccharides. Microbial biotechnology. 2015;8:19-20.

[34] Rice MK, Ruder WC. Creating biological nanomaterials using synthetic biology. Science and Technology of Advanced Materials. 2014;15:014401.

[35] Zhong C, Gurry T, Cheng AA, Downey J, Deng Z, Stultz CM, et al. Self-Assembling MultiComponent Nanofibers for Strong Bioinspired Underwater Adhesives. Nature nanotechnology. 2014;9:858.

[36] Carr PA, Church GM. Genome engineering. Nature biotechnology. 2009;27:1151-62.

[37] Cheng AA, Lu TK. Synthetic biology: an emerging engineering discipline. Annual review of biomedical engineering. 2012;14:155-78.

[38] Ye H, Fussenegger M. Synthetic therapeutic gene circuits in mammalian cells. FEBS letters. 2014;588:2537-44.

[39] Khalil AS, Collins JJ. Synthetic biology: applications come of age. Nature reviews Genetics. 2010;11:367-79.

[40] Wang YH, Wei KY, Smolke CD. Synthetic biology: advancing the design of diverse genetic systems. Annual review of chemical and biomolecular engineering. 2013;4:69-102.

[41] Lutz R, Bujard H. Independent and tight regulation of transcriptional units in Escherichia coli via the LacR/O, the TetR/O and AraC/I1-I2 regulatory elements. Nucleic Acids Res.

1997;25:1203-10.

[42] Khlebnikov A, Risa O, Skaug T, Carrier TA, Keasling JD. Regulatable arabinose-inducible gene expression system with consistent control in all cells of a culture. Journal of bacteriology. 2000;182:7029-34.

[43] Tabor JJ, Levskaya A, Voigt CA. Multichromatic control of gene expression in Escherichia coli. Journal of molecular biology. 2011;405:315-24.

[44] Levskaya A, Chevalier AA, Tabor JJ, Simpson ZB, Lavery LA, Levy M, et al. Synthetic biology: engineering Escherichia coli to see light. Nature. 2005;438:441-2.

[45] Stanton BC, Nielsen AA, Tamsir A, Clancy K, Peterson T, Voigt CA. Genomic mining of prokaryotic repressors for orthogonal logic gates. Nature chemical biology. 2014;10:99-105.

[46] Wegerer A, Sun T, Altenbuchner J. Optimization of an E. coli L-rhamnose-inducible expression vector: test of various genetic module combinations. BMC biotechnology. 2008;8:2.

[47] Lee SK, Keasling JD. A propionate-inducible expression system for enteric bacteria. Applied and environmental microbiology. 2005;71:6856-62. 
[48] Choi YJ, Morel L, Le Francois T, Bourque D, Bourget L, Groleau D, et al. Novel, versatile, and tightly regulated expression system for Escherichia coli strains. Applied and environmental microbiology. 2010;76:5058-66.

[49] Mermod N, Ramos JL, Lehrbach PR, Timmis KN. Vector for regulated expression of cloned genes in a wide range of gram-negative bacteria. Journal of bacteriology. 1986;167:447-54.

[50] Rogers JK, Guzman CD, Taylor ND, Raman S, Anderson K, Church GM. Synthetic biosensors for precise gene control and real-time monitoring of metabolites. Nucleic acids research. 2015;43:7648-60.

[51] Braselmann S, Graninger P, Busslinger M. A selective transcriptional induction system for mammalian cells based on Gal4-estrogen receptor fusion proteins. Proceedings of the National Academy of Sciences of the United States of America. 1993;90:1657-61.

[52] Louvion JF, Havaux-Copf B, Picard D. Fusion of GAL4-VP16 to a steroid-binding domain provides a tool for gratuitous induction of galactose-responsive genes in yeast. Gene. 1993;131:129-34.

[53] Wang Y, O'Malley BW, Jr., Tsai SY, O'Malley BW. A regulatory system for use in gene transfer. Proceedings of the National Academy of Sciences of the United States of America. 1994;91:8180-4.

[54] Christopherson KS, Mark MR, Bajaj V, Godowski PJ. Ecdysteroid-dependent regulation of genes in mammalian cells by a Drosophila ecdysone receptor and chimeric transactivators. Proceedings of the National Academy of Sciences of the United States of America. 1992;89:6314-8.

[55] Weber W, Fux C, Daoud-el Baba M, Keller B, Weber CC, Kramer BP, et al. Macrolidebased transgene control in mammalian cells and mice. Nature biotechnology. 2002;20:901-7.

[56] Fussenegger M, Morris RP, Fux C, Rimann M, von Stockar B, Thompson CJ, et al. Streptogramin-based gene regulation systems for mammalian cells. Nature biotechnology. 2000;18:1203-8.

[57] Gossen M, Bujard H. Tight control of gene expression in mammalian cells by tetracyclineresponsive promoters. Proceedings of the National Academy of Sciences of the United States of America. 1992;89:5547-51.

[58] Gitzinger M, Kemmer C, El-Baba MD, Weber W, Fussenegger M. Controlling transgene expression in subcutaneous implants using a skin lotion containing the apple metabolite phloretin. Proceedings of the National Academy of Sciences of the United States of America. 2009;106:10638-43.

[59] Wang H, Ye H, Xie M, Daoud El-Baba M, Fussenegger M. Cosmetics-triggered percutaneous remote control of transgene expression in mice. Nucleic acids research. 2015;43:e91.

[60] Magari SR, Rivera VM, Iuliucci JD, Gilman M, Cerasoli F, Jr. Pharmacologic control of a humanized gene therapy system implanted into nude mice. The Journal of clinical investigation. 1997; 100:2865-72. 
[61] Wieland M, Fussenegger M. Engineering molecular circuits using synthetic biology in mammalian cells. Annual review of chemical and biomolecular engineering. 2012;3:209-34.

[62] Taylor ND, Garruss AS, Moretti R, Chan S, Arbing MA, Cascio D, et al. Engineering an allosteric transcription factor to respond to new ligands. Nature methods. 2015.

[63] Khalil AS, Lu TK, Bashor CJ, Ramirez CL, Pyenson NC, Joung JK, et al. A synthetic biology framework for programming eukaryotic transcription functions. Cell. 2012;150:647-58.

[64] Perez-Pinera P, Ousterout DG, Brunger JM, Farin AM, Glass KA, Guilak F, et al. Synergistic and tunable human gene activation by combinations of synthetic transcription factors. Nature methods. 2013;10:239-42.

[65] Farzadfard F, Perli SD, Lu TK. Tunable and multifunctional eukaryotic transcription factors based on CRISPR/Cas. ACS synthetic biology. 2013;2:604-13.

[66] Gilbert LA, Larson MH, Morsut L, Liu Z, Brar GA, Torres SE, et al. CRISPR-mediated modular RNA-guided regulation of transcription in eukaryotes. Cell. 2013;154:442-51.

[67] Maeder ML, Linder SJ, Cascio VM, Fu Y, Ho QH, Joung JK. CRISPR RNA-guided activation of endogenous human genes. Nature methods. 2013;10:977-9.

[68] Jusiak B, Cleto S, Perez-Pinera P, Lu TK. Engineering Synthetic Gene Circuits in Living Cells with CRISPR Technology. Trends in biotechnology. 2016.

[69] Pavletich NP, Pabo CO. Zinc finger-DNA recognition: crystal structure of a Zif268-DNA complex at 2.1 A. Science. 1991;252:809-17.

[70] Greisman HA, Pabo CO. A general strategy for selecting high-affinity zinc finger proteins for diverse DNA target sites. Science. 1997;275:657-61.

[71] Sander JD, Dahlborg EJ, Goodwin MJ, Cade L, Zhang F, Cifuentes D, et al. Selection-free zinc-finger-nuclease engineering by context-dependent assembly (CoDA). Nature methods. 2011;8:67-9.

[72] Maeder ML, Thibodeau-Beganny S, Osiak A, Wright DA, Anthony RM, Eichtinger M, et al. Rapid "open-source" engineering of customized zinc-finger nucleases for highly efficient gene modification. Molecular cell. 2008;31:294-301.

[73] Burrill DR, Inniss MC, Boyle PM, Silver PA. Synthetic memory circuits for tracking human cell fate. Genes \& development. 2012;26:1486-97.

[74] Bogdanove AJ, Voytas DF. TAL effectors: customizable proteins for DNA targeting. Science. 2011;333:1843-6.

[75] Boch J, Scholze H, Schornack S, Landgraf A, Hahn S, Kay S, et al. Breaking the code of DNA binding specificity of TAL-type III effectors. Science. 2009;326:1509-12.

[76] Mendenhall EM, Williamson KE, Reyon D, Zou JY, Ram O, Joung JK, et al. Locus-specific editing of histone modifications at endogenous enhancers. Nature biotechnology. 2013;31:11336. 
[77] Maeder ML, Angstman JF, Richardson ME, Linder SJ, Cascio VM, Tsai SQ, et al. Targeted DNA demethylation and activation of endogenous genes using programmable TALE-TET1 fusion proteins. Nature biotechnology. 2013;31:1137-42.

[78] Beumer KJ, Trautman JK, Christian M, Dahlem TJ, Lake CM, Hawley RS, et al. Comparing zinc finger nucleases and transcription activator-like effector nucleases for gene targeting in Drosophila. G3. 2013;3:1717-25.

[79] Doudna JA, Charpentier E. Genome editing. The new frontier of genome engineering with CRISPR-Cas9. Science. 2014;346:1258096.

[80] Chavez A, Scheiman J, Vora S, Pruitt BW, Tuttle M, E PRI, et al. Highly efficient Cas9mediated transcriptional programming. Nature methods. 2015;12:326-8.

[81] Qi LS, Larson MH, Gilbert LA, Doudna JA, Weissman JS, Arkin AP, et al. Repurposing CRISPR as an RNA-guided platform for sequence-specific control of gene expression. Cell. 2013;152:1173-83.

[82] Perez-Pinera P, Kocak DD, Vockley CM, Adler AF, Kabadi AM, Polstein LR, et al. RNAguided gene activation by CRISPR-Cas9-based transcription factors. Nature methods. 2013;10:973-6.

[83] Zetsche B, Volz SE, Zhang F. A split-Cas9 architecture for inducible genome editing and transcription modulation. Nature biotechnology. 2015;33:139-42.

[84] Davis KM, Pattanayak V, Thompson DB, Zuris JA, Liu DR. Small molecule-triggered Cas9 protein with improved genome-editing specificity. Nature chemical biology. 2015;11:316-8.

[85] Nissim L, Perli SD, Fridkin A, Perez-Pinera P, Lu TK. Multiplexed and programmable regulation of gene networks with an integrated RNA and CRISPR/Cas toolkit in human cells. Molecular cell. 2014;54:698-710.

[86] Zalatan JG, Lee ME, Almeida R, Gilbert LA, Whitehead EH, La Russa M, et al. Engineering complex synthetic transcriptional programs with CRISPR RNA scaffolds. Cell. 2015;160:339-50.

[87] Lee YJ, Hoynes-O'Connor A, Leong MC, Moon TS. Programmable control of bacterial gene expression with the combined CRISPR and antisense RNA system. Nucleic acids research. 2016.

[88] Kiani S, Chavez A, Tuttle M, Hall RN, Chari R, Ter-Ovanesyan D, et al. Cas9 gRNA engineering for genome editing, activation and repression. Nature methods. 2015.

[89] Nihongaki Y, Yamamoto S, Kawano F, Suzuki H, Sato M. CRISPR-Cas9-based photoactivatable transcription system. Chemistry \& biology. 2015;22:169-74.

[90] Polstein LR, Gersbach CA. A light-inducible CRISPR-Cas9 system for control of endogenous gene activation. Nature chemical biology. 2015;11:198-200.

[91] Konermann S, Brigham MD, Trevino AE, Hsu PD, Heidenreich M, Cong L, et al. Optical control of mammalian endogenous transcription and epigenetic states. Nature. 2013;500:472-6. 
[92] Hilton IB, D'Ippolito AM, Vockley CM, Thakore PI, Crawford GE, Reddy TE, et al. Epigenome editing by a CRISPR-Cas9-based acetyltransferase activates genes from promoters and enhancers. Nature biotechnology. 2015;33:510-7.

[93] Kearns NA, Pham H, Tabak B, Genga RM, Silverstein NJ, Garber M, et al. Functional annotation of native enhancers with a Cas9-histone demethylase fusion. Nature methods. 2015;12:401-3.

[94] Thakore PI, D'Ippolito AM, Song L, Safi A, Shivakumar NK, Kabadi AM, et al. Highly specific epigenome editing by CRISPR-Cas9 repressors for silencing of distal regulatory elements. Nature methods. 2015;12:1143-9.

[95] Keung AJ, Joung JK, Khalil AS, Collins JJ. Chromatin regulation at the frontier of synthetic biology. Nature reviews Genetics. 2015;16:159-71.

[96] Polstein LR, Perez-Pinera P, Kocak DD, Vockley CM, Bledsoe P, Song L, et al. Genomewide specificity of DNA binding, gene regulation, and chromatin remodeling by TALE- and CRISPR/Cas9-based transcriptional activators. Genome research. 2015;25:1158-69.

[97] Lucks JB, Qi L, Mutalik VK, Wang D, Arkin AP. Versatile RNA-sensing transcriptional regulators for engineering genetic networks. Proceedings of the National Academy of Sciences of the United States of America. 2011;108:8617-22.

[98] Liu CC, Qi L, Lucks JB, Segall-Shapiro TH, Wang D, Mutalik VK, et al. An adaptor from translational to transcriptional control enables predictable assembly of complex regulation. Nature methods. 2012;9:1088-94.

[99] Chappell J, Takahashi MK, Lucks JB. Creating small transcription activating RNAs. Nature chemical biology. 2015;11:214-20.

[100] Wroblewska L, Kitada T, Endo K, Siciliano V, Stillo B, Saito H, et al. Mammalian synthetic circuits with RNA binding proteins for RNA-only delivery. Nature biotechnology. 2015;33:839-41.

[101] Hoynes-O'Connor A, Hinman K, Kirchner L, Moon TS. De novo design of heat-repressible RNA thermosensors in E. coli. Nucleic acids research. 2015;43:6166-79.

[102] Lieb M. Studies of heat-inducible lambda bacteriophage. I. Order of genetic sites and properties of mutant prophages. Journal of molecular biology. 1966;16:149-63.

[103] Walton SP, Wu M, Gredell JA, Chan C. Designing highly active siRNAs for therapeutic applications. The FEBS journal. 2010;277:4806-13.

[104] Man S, Cheng R, Miao C, Gong Q, Gu Y, Lu X, et al. Artificial trans-encoded small noncoding RNAs specifically silence the selected gene expression in bacteria. Nucleic acids research. 2011;39:e50.

[105] Carothers JM, Goler JA, Juminaga D, Keasling JD. Model-driven engineering of RNA devices to quantitatively program gene expression. Science. 2011;334:1716-9. 
[106] Chappell J, Watters KE, Takahashi MK, Lucks JB. A renaissance in RNA synthetic biology: new mechanisms, applications and tools for the future. Current opinion in chemical biology. 2015;28:47-56.

[107] Salis HM. The ribosome binding site calculator. Methods in enzymology. 2011;498:19-42.

[108] Salis HM, Mirsky EA, Voigt CA. Automated design of synthetic ribosome binding sites to control protein expression. Nature biotechnology. 2009;27:946-50.

[109] Mutalik VK, Qi L, Guimaraes JC, Lucks JB, Arkin AP. Rationally designed families of orthogonal RNA regulators of translation. Nature chemical biology. 2012;8:447-54.

[110] Isaacs FJ, Dwyer DJ, Ding C, Pervouchine DD, Cantor CR, Collins JJ. Engineered riboregulators enable post-transcriptional control of gene expression. Nature biotechnology. 2004;22:841-7.

[111] Green AA, Silver PA, Collins JJ, Yin P. Toehold switches: de-novo-designed regulators of gene expression. Cell. 2014;159:925-39.

[112] O'Donoghue $P$, Ling J, Wang YS, Soll D. Upgrading protein synthesis for synthetic biology. Nature chemical biology. 2013;9:594-8.

[113] Des Soye BJ, Patel JR, Isaacs FJ, Jewett MC. Repurposing the translation apparatus for synthetic biology. Current opinion in chemical biology. 2015;28:83-90.

[114] Lajoie MJ, Rovner AJ, Goodman DB, Aerni HR, Haimovich AD, Kuznetsov G, et al. Genomically recoded organisms expand biological functions. Science. 2013;342:357-60.

[115] Arbely E, Torres-Kolbus J, Deiters A, Chin JW. Photocontrol of tyrosine phosphorylation in mammalian cells via genetic encoding of photocaged tyrosine. Journal of the American Chemical Society. 2012;134:11912-5.

[116] Deiters A, Groff D, Ryu Y, Xie J, Schultz PG. A genetically encoded photocaged tyrosine. Angewandte Chemie. 2006;45:2728-31.

[117] Hemphill J, Chou C, Chin JW, Deiters A. Genetically encoded light-activated transcription for spatiotemporal control of gene expression and gene silencing in mammalian cells. Journal of the American Chemical Society. 2013;135:13433-9.

[118] Mandell DJ, Lajoie MJ, Mee MT, Takeuchi R, Kuznetsov G, Norville JE, et al. Biocontainment of genetically modified organisms by synthetic protein design. Nature. 2015;518:55-60.

[119] Liu CC, Schultz PG. Adding new chemistries to the genetic code. Annual review of biochemistry. 2010;79:413-44.

[120] Pirman NL, Barber KW, Aerni HR, Ma NJ, Haimovich AD, Rogulina S, et al. A flexible codon in genomically recoded Escherichia coli permits programmable protein phosphorylation. Nature communications. 2015;6:8130. 
[121] Lajoie MJ, Kosuri S, Mosberg JA, Gregg CJ, Zhang D, Church GM. Probing the limits of genetic recoding in essential genes. Science. 2013;342:361-3.

[122] Lajoie MJ, Soll D, Church GM. Overcoming challenges in engineering the genetic code. Journal of molecular biology. 2015.

[123] Terasaka N, Hayashi G, Katoh T, Suga H. An orthogonal ribosome-tRNA pair via engineering of the peptidyl transferase center. Nature chemical biology. 2014;10:555-7.

[124] Wang K, Neumann H, Peak-Chew SY, Chin JW. Evolved orthogonal ribosomes enhance the efficiency of synthetic genetic code expansion. Nature biotechnology. 2007;25:770-7.

[125] Rackham O, Chin JW. A network of orthogonal ribosome x mRNA pairs. Nature chemical biology. 2005;1:159-66.

[126] Neumann H, Wang K, Davis L, Garcia-Alai M, Chin JW. Encoding multiple unnatural amino acids via evolution of a quadruplet-decoding ribosome. Nature. 2010;464:441-4.

[127] Wang K, Sachdeva A, Cox DJ, Wilf NM, Lang K, Wallace S, et al. Optimized orthogonal translation of unnatural amino acids enables spontaneous protein double-labelling and FRET. Nature chemistry. 2014;6:393-403.

[128] Orelle C, Carlson ED, Szal T, Florin T, Jewett MC, Mankin AS. Protein synthesis by ribosomes with tethered subunits. Nature. 2015;524:119-24.

[129] Amiram M, Haimovich AD, Fan C, Wang YS, Aerni HR, Ntai I, et al. Evolution of translation machinery in recoded bacteria enables multi-site incorporation of nonstandard amino acids. Nature biotechnology. 2015;33:1272-9.

[130] Davis JH, Baker TA, Sauer RT. Small-molecule control of protein degradation using split adaptors. ACS chemical biology. 2011;6:1205-13.

[131] Bonger KM, Chen LC, Liu CW, Wandless TJ. Small-molecule displacement of a cryptic degron causes conditional protein degradation. Nature chemical biology. 2011;7:531-7.

[132] Neklesa TK, Tae HS, Schneekloth AR, Stulberg MJ, Corson TW, Sundberg TB, et al. Small-molecule hydrophobic tagging-induced degradation of HaloTag fusion proteins. Nature chemical biology. 2011;7:538-43.

[133] Cameron DE, Collins JJ. Tunable protein degradation in bacteria. Nature biotechnology. 2014;32:1276-81.

[134] Olson EJ, Tabor JJ. Post-translational tools expand the scope of synthetic biology. Current opinion in chemical biology. 2012;16:300-6.

[135] Isaacs FJ, Carr PA, Wang HH, Lajoie MJ, Sterling B, Kraal L, et al. Precise manipulation of chromosomes in vivo enables genome-wide codon replacement. Science. 2011;333:348-53.

[136] Engler C, Kandzia R, Marillonnet S. A one pot, one step, precision cloning method with high throughput capability. PloS one. 2008;3:e3647. 
[137] Gibson DG, Young L, Chuang RY, Venter JC, Hutchison CA, 3rd, Smith HO. Enzymatic assembly of DNA molecules up to several hundred kilobases. Nature methods. 2009;6:343-5.

[138] Chao R, Yuan Y, Zhao H. Recent advances in DNA assembly technologies. FEMS yeast research. 2014.

[139] Canton B, Labno A, Endy D. Refinement and standardization of synthetic biological parts and devices. Nature biotechnology. 2008;26:787-93.

[140] Brophy JA, Voigt CA. Principles of genetic circuit design. Nature methods. 2014;11:50820.

[141] Olson EJ, Hartsough LA, Landry BP, Shroff R, Tabor JJ. Characterizing bacterial gene circuit dynamics with optically programmed gene expression signals. Nature methods. 2014;11:449-55.

[142] Castillo-Hair SM, Igoshin OA, Tabor JJ. How to train your microbe: methods for dynamically characterizing gene networks. Current opinion in microbiology. 2015;24:113-23.

[143] Mutalik VK, Guimaraes JC, Cambray G, Mai QA, Christoffersen MJ, Martin L, et al. Quantitative estimation of activity and quality for collections of functional genetic elements. Nature methods. 2013;10:347-53.

[144] Huang H, Densmore D. Integration of microfluidics into the synthetic biology design flow. Lab on a chip. 2014;14:3459-74.

[145] Bennett MR, Hasty J. Microfluidic devices for measuring gene network dynamics in single cells. Nature reviews Genetics. 2009;10:628-38.

[146] Linshiz G, Jensen E, Stawski N, Bi C, Elsbree N, Jiao H, et al. End-to-end automated microfluidic platform for synthetic biology: from design to functional analysis. Journal of biological engineering. 2016;10:3.

[147] Ball DA, Lux MW, Adames NR, Peccoud J. Adaptive imaging cytometry to estimate parameters of gene networks models in systems and synthetic biology. PloS one. 2014;9:e107087.

[148] Xia B, Bhatia S, Bubenheim B, Dadgar M, Densmore D, Anderson JC. Developer's and user's guide to Clotho v2.0 A software platform for the creation of synthetic biological systems. Methods in enzymology. 2011;498:97-135.

[149] Bilitchenko L, Liu A, Cheung S, Weeding E, Xia B, Leguia M, et al. Eugene--a domain specific language for specifying and constraining synthetic biological parts, devices, and systems. PloS one. 2011;6:e18882.

[150] Quinn JY, Cox RS, 3rd, Adler A, Beal J, Bhatia S, Cai Y, et al. SBOL Visual: A Graphical Language for Genetic Designs. PLoS biology. 2015;13:e1002310.

[151] Packer MS, Liu DR. Methods for the directed evolution of proteins. Nature reviews Genetics. 2015;16:379-94. 
[152] Ellefson JW, Meyer AJ, Hughes RA, Cannon JR, Brodbelt JS, Ellington AD. Directed evolution of genetic parts and circuits by compartmentalized partnered replication. Nature biotechnology. 2014;32:97-101.

[153] Ellis T, Wang X, Collins JJ. Diversity-based, model-guided construction of synthetic gene networks with predicted functions. Nature biotechnology. 2009;27:465-71.

[154] Rosenfeld N, Young JW, Alon U, Swain PS, Elowitz MB. Accurate prediction of gene feedback circuit behavior from component properties. Molecular systems biology. 2007;3:143.

[155] Wei P, Wong WW, Park JS, Corcoran EE, Peisajovich SG, Onuffer JJ, et al. Bacterial virulence proteins as tools to rewire kinase pathways in yeast and immune cells. Nature. 2012;488:384-8.

[156] Bashor CJ, Helman NC, Yan S, Lim WA. Using engineered scaffold interactions to reshape MAP kinase pathway signaling dynamics. Science. 2008;319:1539-43.

[157] Ando HL, S.; Pires, D. P.; Lu, T. K. Engineering Modular Viral Scaffolds for Targeted Bacterial Population Editing. Cell Systems. 2015;1:187-96.

[158] Li Y, Jiang Y, Chen H, Liao W, Li Z, Weiss R, et al. Modular construction of mammalian gene circuits using TALE transcriptional repressors. Nature chemical biology. 2015;11:207-13.

[159] Davis JH, Rubin AJ, Sauer RT. Design, construction and characterization of a set of insulated bacterial promoters. Nucleic acids research. 2011;39:1131-41.

[160] Qi L, Haurwitz RE, Shao W, Doudna JA, Arkin AP. RNA processing enables predictable programming of gene expression. Nature biotechnology. 2012;30:1002-6.

[161] Lou C, Stanton B, Chen YJ, Munsky B, Voigt CA. Ribozyme-based insulator parts buffer synthetic circuits from genetic context. Nature biotechnology. 2012;30:1137-42.

[162] Oppenheim DS, Yanofsky C. Translational coupling during expression of the tryptophan operon of Escherichia coli. Genetics. 1980;95:785-95.

[163] Makoff AJ, Smallwood AE. The use of two-cistron constructions in improving the expression of a heterologous gene in E. coli. Nucleic acids research. 1990;18:1711-8.

[164] Mutalik VK, Guimaraes JC, Cambray G, Lam C, Christoffersen MJ, Mai QA, et al. Precise and reliable gene expression via standard transcription and translation initiation elements. Nature methods. 2013;10:354-60.

[165] Ramirez CL, Foley JE, Wright DA, Muller-Lerch F, Rahman SH, Cornu TI, et al. Unexpected failure rates for modular assembly of engineered zinc fingers. Nature methods. 2008;5:374-5.

[166] Mishra D, Rivera PM, Lin A, Del Vecchio D, Weiss R. A load driver device for engineering modularity in biological networks. Nature biotechnology. 2014;32:1268-75.

[167] Del Vecchio D. Modularity, context-dependence, and insulation in engineered biological circuits. Trends in biotechnology. 2015;33:111-9. 
[168] Klumpp S, Zhang Z, Hwa T. Growth rate-dependent global effects on gene expression in bacteria. Cell. 2009;139:1366-75.

[169] Tan C, Marguet P, You L. Emergent bistability by a growth-modulating positive feedback circuit. Nature chemical biology. 2009;5:842-8.

[170] Carrera J, Rodrigo G, Singh V, Kirov B, Jaramillo A. Empirical model and in vivo characterization of the bacterial response to synthetic gene expression show that ribosome allocation limits growth rate. Biotechnology journal. 2011;6:773-83.

[171] Scott M, Gunderson CW, Mateescu EM, Zhang Z, Hwa T. Interdependence of cell growth and gene expression: origins and consequences. Science. 2010;330:1099-102.

[172] Weisse AY, Oyarzun DA, Danos V, Swain PS. Mechanistic links between cellular tradeoffs, gene expression, and growth. Proceedings of the National Academy of Sciences of the United States of America. 2015;112:E1038-47.

[173] Ceroni F, Algar R, Stan GB, Ellis T. Quantifying cellular capacity identifies gene expression designs with reduced burden. Nature methods. 2015;12:415-8.

[174] Segall-Shapiro TH, Meyer AJ, Ellington AD, Sontag ED, Voigt CA. A 'resource allocator' for transcription based on a highly fragmented T7 RNA polymerase. Molecular systems biology. $2014 ; 10: 742$.

[175] Nevozhay D, Zal T, Balazsi G. Transferring a synthetic gene circuit from yeast to mammalian cells. Nature communications. 2013;4:1451.

[176] Stanton BC, Siciliano V, Ghodasara A, Wroblewska L, Clancy K, Trefzer AC, et al. Systematic transfer of prokaryotic sensors and circuits to mammalian cells. ACS synthetic biology. 2014;3:880-91.

[177] Prindle A, Selimkhanov J, Danino T, Samayoa P, Goldberg A, Bhatia SN, et al. Genetic Circuits in Salmonella typhimurium. ACS synthetic biology. 2012;1:458-64.

[178] Kushwaha M, Salis HM. A portable expression resource for engineering cross-species genetic circuits and pathways. Nature communications. 2015;6:7832.

[179] Purcell O, Lu TK. Synthetic analog and digital circuits for cellular computation and memory. Current Opinion in Biotechnology. 2014;29:146-55.

[180] Benenson Y. Biomolecular computing systems: principles, progress and potential. Nat Rev Genet. 2012;13:455-68.

[181] Greber D, Fussenegger M. Mammalian synthetic biology: Engineering of sophisticated gene networks. Journal of Biotechnology. 2007;130:329-45.

[182] Roquet N, Lu TK. Digital and analog gene circuits for biotechnology. Biotechnology Journal. 2014;9:597-608.

[183] Becskei A, Séraphin B, Serrano L. Positive feedback in eukaryotic gene networks: cell differentiation by graded to binary response conversion. The EMBO Journal. 2001;20:2528-35. 
[184] Ajo-Franklin CM, Drubin DA, Eskin JA, Gee EPS, Landgraf D, Phillips I, et al. Rational design of memory in eukaryotic cells. Genes \& Development. 2007;21:2271-6.

[185] Atkinson MR, Savageau MA, Myers JT, Ninfa AJ. Development of Genetic Circuitry Exhibiting Toggle Switch or Oscillatory Behavior in Escherichia coli. Cell. 2003;113:597-607.

[186] Chen D, Arkin AP. Sequestration-based bistability enables tuning of the switching boundaries and design of a latch. Molecular Systems Biology. 2012;8.

[187] Isaacs FJ, Hasty J, Cantor CR, Collins JJ. Prediction and measurement of an autoregulatory genetic module. Proceedings of the National Academy of Sciences. 2003;100:7714-9.

[188] Kobayashi H, Kærn M, Araki M, Chung K, Gardner TS, Cantor CR, et al. Programmable cells: Interfacing natural and engineered gene networks. Proceedings of the National Academy of Sciences of the United States of America. 2004;101:8414-9.

[189] Kramer BP, Viretta AU, Baba MD-E, Aubel D, Weber W, Fussenegger M. An engineered epigenetic transgene switch in mammalian cells. Nat Biotech. 2004;22:867-70.

[190] Bonnet J, Subsoontorn P, Endy D. Rewritable digital data storage in live cells via engineered control of recombination directionality. Proceedings of the National Academy of Sciences. 2012;109:8884-9.

[191] Ham TS, Lee SK, Keasling JD, Arkin AP. Design and Construction of a Double Inversion Recombination Switch for Heritable Sequential Genetic Memory. PLoS ONE. 2008;3:e2815.

[192] Moon TS, Clarke EJ, Groban ES, Tamsir A, Clark RM, Eames M, et al. Construction of a Genetic Multiplexer to Toggle between Chemosensory Pathways in Escherichia coli. Journal of Molecular Biology. 2011;406:215-27.

[193] Friedland AE, Lu TK, Wang X, Shi D, Church G, Collins JJ. Synthetic gene networks that count. Science. 2009;324:1199-202.

[194] Yang L, Nielsen AA, Fernandez-Rodriguez J, McClune CJ, Laub MT, Lu TK, et al. Permanent genetic memory with >1-byte capacity. Nature methods. 2014;11:1261-6.

[195] Siuti P, Yazbek J, Lu TK. Synthetic circuits integrating logic and memory in living cells. Nature biotechnology. 2013;31:448-52.

[196] Mimee M, Tucker AC, Voigt CA, Lu TK. Programming a Human Commensal Bacterium, Bacteroides thetaiotaomicron, to Sense and Respond to Stimuli in the Murine Gut Microbiota. Cell Systems. 2015;1:62-71.

[197] Bonnet J, Yin P, Ortiz ME, Subsoontorn P, Endy D. Amplifying genetic logic gates. Science. 2013;340:599-603.

[198] Kramer BP, Fischer C, Fussenegger M. BioLogic gates enable logical transcription control in mammalian cells. Biotechnology and Bioengineering. 2004;87:478-84. 
[199] Nielsen AA, Voigt CA. Multi-input CRISPR/Cas genetic circuits that interface host regulatory networks. Molecular Systems Biology. 2014;10.

[200] Leisner M, Bleris L, Lohmueller J, Xie Z, Benenson Y. Rationally designed logic integration of regulatory signals in mammalian cells. Nat Nano. 2010;5:666-70.

[201] Rinaudo K, Bleris L, Maddamsetti R, Subramanian S, Weiss R, Benenson Y. A universal RNAi-based logic evaluator that operates in mammalian cells. Nat Biotech. 2007;25:795-801.

[202] Xie Z, Wroblewska L, Prochazka L, Weiss R, Benenson Y. Multi-Input RNAi-Based Logic Circuit for Identification of Specific Cancer Cells. Science. 2011;333:1307-11.

[203] Rackham O, Chin JW. Cellular Logic with Orthogonal Ribosomes. Journal of the American Chemical Society. 2005;127:17584-5.

[204] Win MN, Smolke CD. Higher-Order Cellular Information Processing with Synthetic RNA Devices. Science. 2008;322:456-60.

[205] Dueber JE, Yeh BJ, Chak K, Lim WA. Reprogramming Control of an Allosteric Signaling Switch Through Modular Recombination. Science. 2003;301:1904-8.

[206] Moon TS, Lou C, Tamsir A, Stanton BC, Voigt CA. Genetic programs constructed from layered logic gates in single cells. Nature. 2012;491:249-53.

[207] Tabor JJ, Salis HM, Simpson ZB, Chevalier AA, Levskaya A, Marcotte EM, et al. A Synthetic Genetic Edge Detection Program. Cell. 2009;137:1272-81.

[208] Regot S, Macia J, Conde N, Furukawa K, Kjellen J, Peeters T, et al. Distributed biological computation with multicellular engineered networks. Nature. 2011;469:207-11.

[209] Giorgetti L, Siggers T, Tiana G, Caprara G, Notarbartolo S, Corona T, et al. Noncooperative Interactions between Transcription Factors and Clustered DNA Binding Sites Enable Graded Transcriptional Responses to Environmental Inputs. Molecular Cell. 2010;37:418-28.

[210] Lahav G, Rosenfeld N, Sigal A, Geva-Zatorsky N, Levine AJ, Elowitz MB, et al. Dynamics of the p53-Mdm2 feedback loop in individual cells. Nat Genet. 2004;36:147-50.

[211] Nevozhay D, Adams RM, Murphy KF, Josic K, Balazsi G. Negative autoregulation linearizes the dose-response and suppresses the heterogeneity of gene expression. Proceedings of the National Academy of Sciences of the United States of America. 2009;106:5123-8.

[212] Daniel R, Rubens JR, Sarpeshkar R, Lu TK. Synthetic analog computation in living cells. Nature. 2013;497:619-23.

[213] Lu TK, Khalil AS, Collins JJ. Next-generation synthetic gene networks. Nature biotechnology. 2009;27:1139-50.

[214] Siuti P, Yazbek J, Lu TK. Synthetic circuits integrating logic and memory in living cells. Nat Biotech. 2013;31:448-52. 
[215] Farzadfard F, Lu TK. Synthetic biology. Genomically encoded analog memory with precise in vivo DNA writing in living cell populations. Science. 2014;346:1256272.

[216] Kollmann M, Lovdok L, Bartholome K, Timmer J, Sourjik V. Design principles of a bacterial signalling network. Nature. 2005;438:504-7.

[217] Igoshin OA, Brody MS, Price CW, Savageau MA. Distinctive topologies of partnerswitching signaling networks correlate with their physiological roles. Journal of molecular biology. 2007;369:1333-52.

[218] Cagatay T, Turcotte M, Elowitz MB, Garcia-Ojalvo J, Suel GM. Architecture-dependent noise discriminates functionally analogous differentiation circuits. Cell. 2009;139:512-22.

[219] Madar D, Dekel E, Bren A, Alon U. Negative auto-regulation increases the input dynamicrange of the arabinose system of Escherichia coli. BMC systems biology. 2011;5:111.

[220] Rosenfeld N, Elowitz MB, Alon U. Negative autoregulation speeds the response times of transcription networks. Journal of molecular biology. 2002;323:785-93.

[221] Shen-Orr SS, Milo R, Mangan S, Alon U. Network motifs in the transcriptional regulation network of Escherichia coli. Nature genetics. 2002;31:64-8.

[222] Mangan S, Alon U. Structure and function of the feed-forward loop network motif. Proceedings of the National Academy of Sciences of the United States of America. 2003;100:11980-5.

[223] Entus R, Aufderheide B, Sauro HM. Design and implementation of three incoherent feedforward motif based biological concentration sensors. Systems and synthetic biology. 2007;1:119-28.

[224] Basu S, Mehreja R, Thiberge S, Chen MT, Weiss R. Spatiotemporal control of gene expression with pulse-generating networks. Proceedings of the National Academy of Sciences of the United States of America. 2004;101:6355-60.

[225] Mangan S, Itzkovitz S, Zaslaver A, Alon U. The incoherent feed-forward loop accelerates the response-time of the gal system of Escherichia coli. Journal of molecular biology. 2006;356:1073-81.

[226] Kaplan S, Bren A, Dekel E, Alon U. The incoherent feed-forward loop can generate nonmonotonic input functions for genes. Molecular systems biology. 2008;4:203.

[227] Wang LZ, Wu F, Flores K, Lai YC, Wang X. Build to understand: synthetic approaches to biology. Integrative biology : quantitative biosciences from nano to macro. 2015.

[228] An W, Chin JW. Synthesis of orthogonal transcription-translation networks. Proceedings of the National Academy of Sciences of the United States of America. 2009;106:8477-82.

[229] Novak B, Tyson JJ. Design principles of biochemical oscillators. Nature reviews Molecular cell biology. 2008;9:981-91. 
[230] Tsai TY, Choi YS, Ma W, Pomerening JR, Tang C, Ferrell JE, Jr. Robust, tunable biological oscillations from interlinked positive and negative feedback loops. Science.

2008;321:126-9.

[231] Stricker J, Cookson S, Bennett MR, Mather WH, Tsimring LS, Hasty J. A fast, robust and tunable synthetic gene oscillator. Nature. 2008;456:516-9.

[232] Danino T, Mondragon-Palomino O, Tsimring L, Hasty J. A synchronized quorum of genetic clocks. Nature. 2010;463:326-30.

[233] Prindle A, Selimkhanov J, Li H, Razinkov I, Tsimring LS, Hasty J. Rapid and tunable posttranslational coupling of genetic circuits. Nature. 2014;508:387-91.

[234] Young MW, Kay SA. Time zones: a comparative genetics of circadian clocks. Nature reviews Genetics. 2001;2:702-15.

[235] Glass L. Synchronization and rhythmic processes in physiology. Nature. 2001;410:277-84.

[236] Chen AH, Lubkowicz D, Yeong V, Chang RL, Silver PA. Transplantability of a circadian clock to a noncircadian organism. Science advances. 2015;1.

[237] Pattanayak GK, Lambert G, Bernat K, Rust MJ. Controlling the Cyanobacterial Clock by Synthetically Rewiring Metabolism. Cell reports. 2015.

[238] Liu J, Prindle A, Humphries J, Gabalda-Sagarra M, Asally M, Lee DY, et al. Metabolic codependence gives rise to collective oscillations within biofilms. Nature. 2015;523:550-4.

[239] Thaiss CA, Zeevi D, Levy M, Zilberman-Schapira G, Suez J, Tengeler AC, et al. Transkingdom control of microbiota diurnal oscillations promotes metabolic homeostasis. Cell. 2014;159:514-29.

[240] Purcell O, Savery NJ, Grierson CS, di Bernardo M. A comparative analysis of synthetic genetic oscillators. Journal of the Royal Society, Interface / the Royal Society. 2010;7:1503-24.

[241] Cox CD, McCollum JM, Austin DW, Allen MS, Dar RD, Simpson ML. Frequency domain analysis of noise in simple gene circuits. Chaos. 2006;16:026102.

[242] Mettetal JT, Muzzey D, Gomez-Uribe C, van Oudenaarden A. The frequency dependence of osmo-adaptation in Saccharomyces cerevisiae. Science. 2008;319:482-4.

[243] Muzzey D, Gomez-Uribe CA, Mettetal JT, van Oudenaarden A. A systems-level analysis of perfect adaptation in yeast osmoregulation. Cell. 2009;138:160-71.

[244] Kotas ME, Medzhitov R. Homeostasis, inflammation, and disease susceptibility. Cell. 2015;160:816-27.

[245] Kemmer C, Gitzinger M, Daoud-El Baba M, Djonov V, Stelling J, Fussenegger M. Selfsufficient control of urate homeostasis in mice by a synthetic circuit. Nature biotechnology. 2010;28:355-60.

[246] Rossger K, Charpin-El-Hamri G, Fussenegger M. A closed-loop synthetic gene circuit for the treatment of diet-induced obesity in mice. Nature communications. 2013;4:2825. 
[247] Ye H, Charpin-El Hamri G, Zwicky K, Christen M, Folcher M, Fussenegger M. Pharmaceutically controlled designer circuit for the treatment of the metabolic syndrome. Proceedings of the National Academy of Sciences of the United States of America. 2013;110:141-6.

[248] Rossger K, Charpin-El Hamri G, Fussenegger M. Reward-based hypertension control by a synthetic brain-dopamine interface. Proceedings of the National Academy of Sciences of the United States of America. 2013;110:18150-5.

[249] Bassik MC, Kampmann M, Lebbink RJ, Wang S, Hein MY, Poser I, et al. A systematic mammalian genetic interaction map reveals pathways underlying ricin susceptibility. Cell. 2013;152:909-22.

[250] Wong AS, Choi GC, Cheng AA, Purcell O, Lu TK. Massively parallel high-order combinatorial genetics in human cells. Nature biotechnology. 2015;33:952-61.

[251] Cheng AA, Ding H, Lu TK. Enhanced killing of antibiotic-resistant bacteria enabled by massively parallel combinatorial genetics. Proceedings of the National Academy of Sciences of the United States of America. 2014;111:12462-7.

[252] Wong AS, Choi GC, Cui CH, Pregernig G, Milani P, Adam M, et al. Multiplexed barcoded CRISPR-Cas9 screening enabled by CombiGEM. PNAS. 2016.

[253] Woolston BM, Edgar S, Stephanopoulos G. Metabolic engineering: past and future. Annual review of chemical and biomolecular engineering. 2013;4:259-88.

[254] Nielsen J, Keasling JD. Synergies between synthetic biology and metabolic engineering. Nature biotechnology. 2011;29:693-5.

[255] Covert MW, Palsson BO. Transcriptional regulation in constraints-based metabolic models of Escherichia coli. The Journal of biological chemistry. 2002;277:28058-64.

[256] Gadkar KG, Doyle lii FJ, Edwards JS, Mahadevan R. Estimating optimal profiles of genetic alterations using constraint-based models. Biotechnology and bioengineering. 2005;89:243-51.

[257] Hjersted JL, Henson MA. Optimization of fed-batch Saccharomyces cerevisiae fermentation using dynamic flux balance models. Biotechnology progress. 2006;22:1239-48.

[258] Anesiadis N, Cluett WR, Mahadevan R. Dynamic metabolic engineering for increasing bioprocess productivity. Metabolic engineering. 2008;10:255-66.

[259] Anesiadis N, Kobayashi H, Cluett WR, Mahadevan R. Analysis and design of a genetic circuit for dynamic metabolic engineering. ACS synthetic biology. 2013;2:442-52.

[260] Zhang F, Carothers JM, Keasling JD. Design of a dynamic sensor-regulator system for production of chemicals and fuels derived from fatty acids. Nature biotechnology. 2012;30:3549.

[261] Dahl RH, Zhang F, Alonso-Gutierrez J, Baidoo E, Batth TS, Redding-Johanson AM, et al. Engineering dynamic pathway regulation using stress-response promoters. Nature biotechnology. 2013;31:1039-46. 
[262] Venayak N, Anesiadis N, Cluett WR, Mahadevan R. Engineering metabolism through dynamic control. Current opinion in biotechnology. 2015;34:142-52.

[263] Dietrich JA, McKee AE, Keasling JD. High-throughput metabolic engineering: advances in small-molecule screening and selection. Annual review of biochemistry. 2010;79:563-90.

[264] Esvelt KM, Carlson JC, Liu DR. A system for the continuous directed evolution of biomolecules. Nature. 2011;472:499-503.

[265] Michener JK, Smolke CD. High-throughput enzyme evolution in Saccharomyces cerevisiae using a synthetic RNA switch. Metabolic engineering. 2012;14:306-16.

[266] Gallagher RR, Li Z, Lewis AO, Isaacs FJ. Rapid editing and evolution of bacterial genomes using libraries of synthetic DNA. Nature protocols. 2014;9:2301-16.

[267] Wang HH, Kim H, Cong L, Jeong J, Bang D, Church GM. Genome-scale promoter engineering by coselection MAGE. Nature methods. 2012;9:591-3.

[268] Wang HH, Isaacs FJ, Carr PA, Sun ZZ, Xu G, Forest CR, et al. Programming cells by multiplex genome engineering and accelerated evolution. Nature. 2009;460:894-8.

[269] Mustafi N, Grunberger A, Kohlheyer D, Bott M, Frunzke J. The development and application of a single-cell biosensor for the detection of I-methionine and branched-chain amino acids. Metabolic engineering. 2012;14:449-57.

[270] Binder S, Schendzielorz G, Stabler N, Krumbach K, Hoffmann K, Bott M, et al. A highthroughput approach to identify genomic variants of bacterial metabolite producers at the singlecell level. Genome biology. 2012;13:R40.

[271] Shou W, Ram S, Vilar JM. Synthetic cooperation in engineered yeast populations. Proceedings of the National Academy of Sciences of the United States of America. 2007; 104:1877-82.

[272] Balagadde FK, Song H, Ozaki J, Collins $\mathrm{CH}$, Barnet M, Arnold FH, et al. A synthetic Escherichia coli predator-prey ecosystem. Molecular systems biology. 2008;4:187.

[273] Kerner A, Park J, Williams A, Lin XN. A programmable Escherichia coli consortium via tunable symbiosis. PloS one. 2012;7:e34032.

[274] Mee MT, Collins JJ, Church GM, Wang HH. Syntrophic exchange in synthetic microbial communities. Proceedings of the National Academy of Sciences of the United States of America. 2014;111:E2149-56.

[275] Basu S, Gerchman Y, Collins CH, Arnold FH, Weiss R. A synthetic multicellular system for programmed pattern formation. Nature. 2005;434:1130-4.

[276] Kong W, Celik V, Liao C, Hua Q, Lu T. Programming the group behaviors of bacterial communities with synthetic cellular communication. Bioresources and Bioprocessing. 2014;1.

[277] Chen Y, Kim JK, Hirning AJ, Josic K, Bennett MR. SYNTHETIC BIOLOGY. Emergent genetic oscillations in a synthetic microbial consortium. Science. 2015;349:986-9. 
[278] Dandekar AA, Chugani S, Greenberg EP. Bacterial quorum sensing and metabolic incentives to cooperate. Science. 2012;338:264-6.

[279] Zhang F, Kwan A, Xu A, Suel GM. A Synthetic Quorum Sensing System Reveals a Potential Private Benefit for Public Good Production in a Biofilm. PloS one. 2015;10:e0132948.

[280] Davis RM, Muller RY, Haynes KA. Can the natural diversity of quorum-sensing advance synthetic biology? Frontiers in bioengineering and biotechnology. 2015;3:30.

[281] Wu F, Menn DJ, Wang X. Quorum-sensing crosstalk-driven synthetic circuits: from unimodality to trimodality. Chemistry \& biology. 2014;21:1629-38.

[282] Hsiao EY, McBride SW, Hsien S, Sharon G, Hyde ER, McCue T, et al. Microbiota modulate behavioral and physiological abnormalities associated with neurodevelopmental disorders. Cell. 2013;155:1451-63.

[283] Turnbaugh PJ, Ley RE, Mahowald MA, Magrini V, Mardis ER, Gordon JI. An obesityassociated gut microbiome with increased capacity for energy harvest. Nature. 2006;444:102731.

[284] Tai N, Wong FS, Wen L. The role of gut microbiota in the development of type 1, type 2 diabetes mellitus and obesity. Reviews in endocrine \& metabolic disorders. 2015;16:55-65.

[285] Frank DN, St Amand AL, Feldman RA, Boedeker EC, Harpaz N, Pace NR. Molecularphylogenetic characterization of microbial community imbalances in human inflammatory bowel diseases. Proceedings of the National Academy of Sciences of the United States of America. 2007; 104:13780-5.

[286] Swanson HI. Drug Metabolism by the Host and Gut Microbiota: A Partnership or Rivalry? Drug metabolism and disposition: the biological fate of chemicals. 2015;43:1499-504.

[287] Schmidt K, Cowen PJ, Harmer CJ, Tzortzis G, Errington S, Burnet PW. Prebiotic intake reduces the waking cortisol response and alters emotional bias in healthy volunteers.

Psychopharmacology. 2015;232:1793-801.

[288] Tillisch K, Labus J, Kilpatrick L, Jiang Z, Stains J, Ebrat B, et al. Consumption of fermented milk product with probiotic modulates brain activity. Gastroenterology.

2013;144:1394-401, 401 e1-4.

[289] Kotula JW, Kerns SJ, Shaket LA, Siraj L, Collins JJ, Way JC, et al. Programmable bacteria detect and record an environmental signal in the mammalian gut. Proceedings of the National Academy of Sciences of the United States of America. 2014;111:4838-43.

[290] Qin J, Li R, Raes J, Arumugam M, Burgdorf KS, Manichanh C, et al. A human gut microbial gene catalogue established by metagenomic sequencing. Nature. 2010;464:59-65.

[291] Danino T, Prindle A, Kwong GA, Skalak M, Li H, Allen K, et al. Programmable probiotics for detection of cancer in urine. Science translational medicine. 2015;7:289ra84.

[292] Cuiv PO, Smith WJ, Pottenger S, Burman S, Shanahan ER, Morrison M. Isolation of Genetically Tractable Most-Wanted Bacteria by Metaparental Mating. Scientific reports. 2015;5. 
[293] Citorik RJ, Mimee M, Lu TK. Sequence-specific antimicrobials using efficiently delivered RNA-guided nucleases. Nature biotechnology. 2014;32:1141-5.

[294] Geva-Zatorsky N, Alvarez D, Hudak JE, Reading NC, Erturk-Hasdemir D, Dasgupta S, et al. In vivo imaging and tracking of host-microbiota interactions via metabolic labeling of gut anaerobic bacteria. Nature medicine. 2015;21:1091-100.

[295] Myhrvold C, Kotula JW, Hicks WM, Conway NJ, Silver PA. A distributed cell division counter reveals growth dynamics in the gut microbiota. Nature communications. 2015;6.

[296] Zomorrodi AR, Segre D. Synthetic Ecology of Microbes: Mathematical Models and Applications. Journal of molecular biology. 2015.

[297] Lee JH, Daugharthy ER, Scheiman J, Kalhor R, Yang JL, Ferrante TC, et al. Highly multiplexed subcellular RNA sequencing in situ. Science. 2014;343:1360-3.

[298] Ellis DI, Goodacre R. Metabolomics-assisted synthetic biology. Current opinion in biotechnology. 2012;23:22-8.

[299] Blazier AS, Papin JA. Integration of expression data in genome-scale metabolic network reconstructions. Frontiers in physiology. 2012;3:299.

[300] Xu P, Li L, Zhang F, Stephanopoulos G, Koffas M. Improving fatty acids production by engineering dynamic pathway regulation and metabolic control. Proceedings of the National Academy of Sciences of the United States of America. 2014;111:11299-304.

[301] Orth JD, Thiele I, Palsson BO. What is flux balance analysis? Nature biotechnology. 2010;28:245-8.

[302] Liu H, Lu T. Autonomous production of 1,4-butanediol via a de novo biosynthesis pathway in engineered Escherichia coli. Metabolic engineering. 2015;29:135-41. 


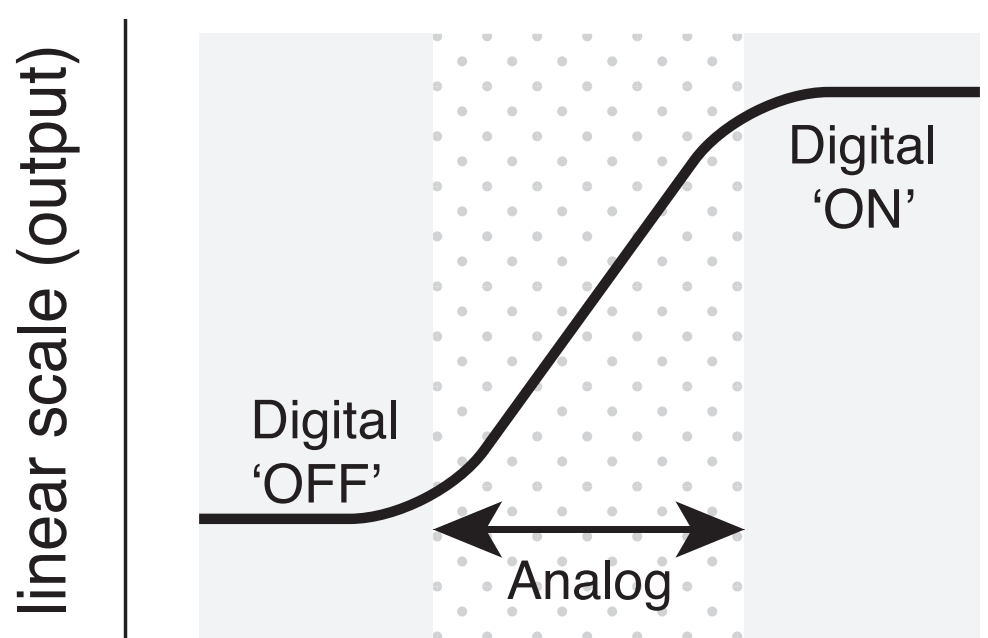

Figure 1

\section{Digital regime} Analog regime

log scale (input)

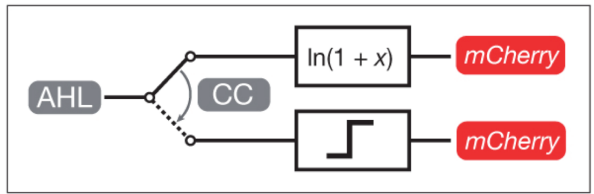

d
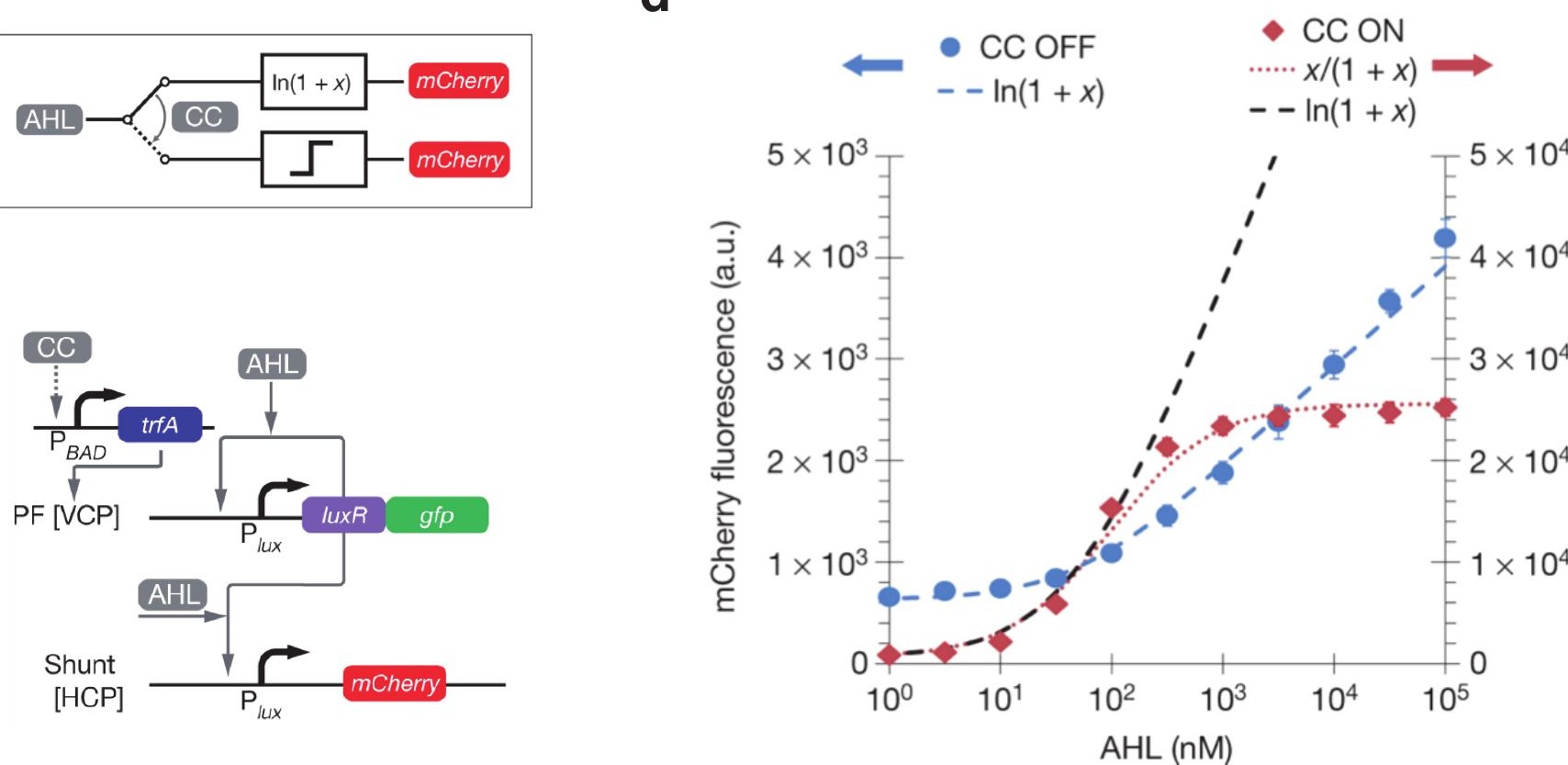
a

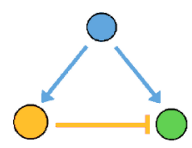

28)

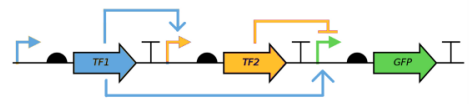

28)

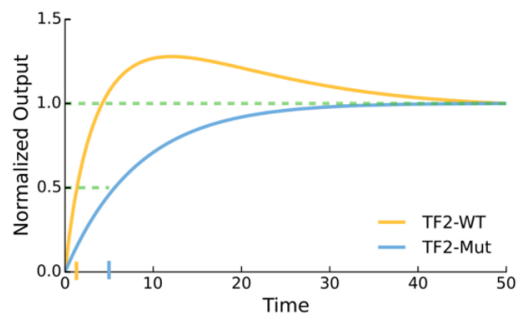

b
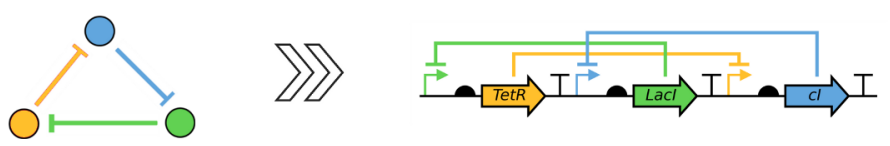

88

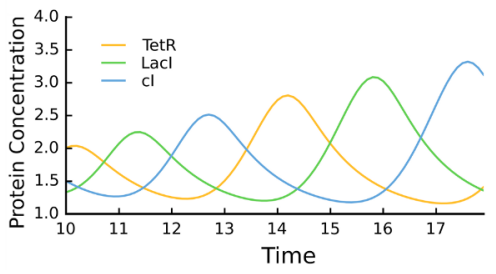




\section{Static}

a

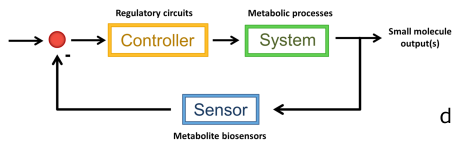

b

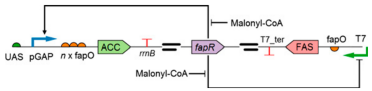

C

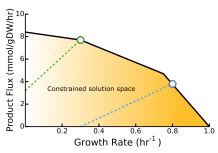

d

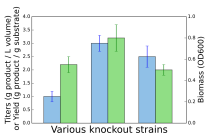

e

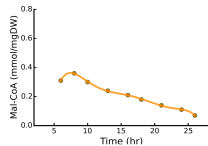

$\sum D$

Dynamic
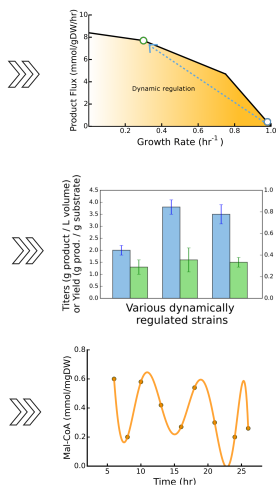
Conceptual Model

a

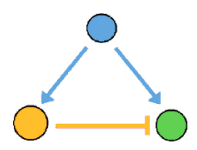

38

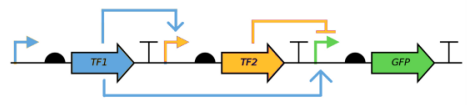

38)

b

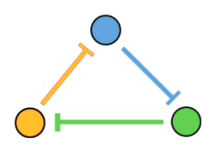

Biological Implementation

\section{Circuit Characterization}
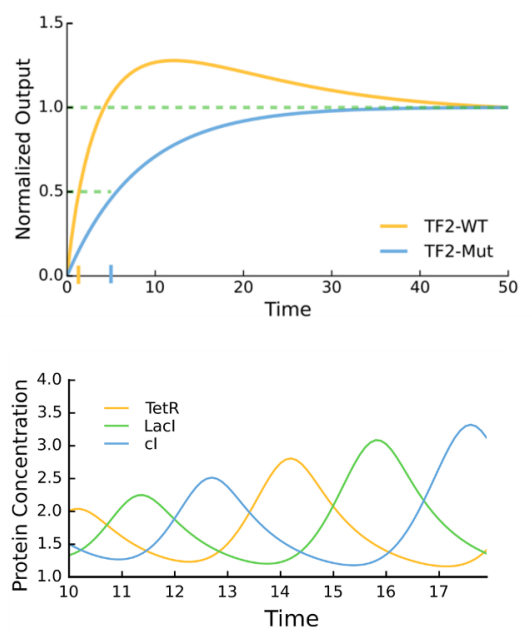